\title{
Article
}

\section{Rapamycin Ameliorates Defects in Mitochondrial Fission and Mitophagy in Glioblastoma Cells}

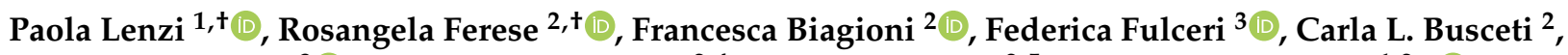 \\ Alessandra Falleni ${ }^{3}\left(\mathbb{D}\right.$, Stefano Gambardella ${ }^{2,4}$, Alessandro Frati ${ }^{2,5}$ and Francesco Fornai ${ }^{1,2, *(D)}$ \\ 1 Department of Translational Research and New Technologies in Medicine and Surgery, University of Pisa, \\ Via Roma 55, 56126 Pisa, Italy; paola.lenzi@unipi.it \\ 2 I.R.C.C.S. Neuromed, Via Atinense 18, 86077 Pozzilli (IS), Italy; ferese.rosangela@gmail.com (R.F.); \\ francesca.biagioni@neuromed.it (F.B.); carla.busceti@neuromed.it (C.L.B.); \\ stefano.gambardella@neuromed.it (S.G.); alessandro.frati@uniroma1.it (A.F.) \\ 3 Department of Clinical and Experimental Medicine University of Pisa, via Roma 55, 56126 Pisa, Italy; \\ federica.fulceri@unipi.it (F.F.); alessandra.falleni@unipi.it (A.F.) \\ 4 Department of Biomolecular Sciences, University of Urbino “Carlo Bo", Piazza S. Andrea 34, \\ 61029 Urbino (PU), Italy \\ 5 Neurosurgery Division, Human Neurosciences Department, Sapienza University, 00135 Roma, Italy. \\ * Correspondence: francesco.fornai@neuromed.it or francesco.fornai@unipi.it \\ $\dagger$ These authors equally contributed to the present work.
}

Citation: Lenzi, P.; Ferese, R.;

Biagioni, F.; Fulceri, F.; Busceti, C.L.; Falleni, A.; Gambardella, S.; Frati, A.; Fornai, F. Rapamycin Ameliorates Defects in Mitochondrial Fission and Mitophagy in Glioblastoma Cells. Int. J. Mol. Sci. 2021, 22, 5379. https:// doi.org/10.3390/ijms22105379

Academic Editor: Masahiro Morita

Received: 22 April 2021

Accepted: 18 May 2021

Published: 20 May 2021

Publisher's Note: MDPI stays neutral with regard to jurisdictional claims in published maps and institutional affiliations.

Copyright: (c) 2021 by the authors. Licensee MDPI, Basel, Switzerland. This article is an open access article distributed under the terms and conditions of the Creative Commons Attribution (CC BY) license (https:// creativecommons.org/licenses/by/ $4.0 /)$.

\begin{abstract}
Glioblastoma (GBM) cells feature mitochondrial alterations, which are documented and quantified in the present study, by using ultrastructural morphometry. Mitochondrial impairment, which roughly occurs in half of the organelles, is shown to be related to mTOR overexpression and autophagy suppression. The novelty of the present study consists of detailing an mTOR-dependent mitophagy occlusion, along with suppression of mitochondrial fission. These phenomena contribute to explain the increase in altered mitochondria reported here. Administration of the mTOR inhibitor rapamycin rescues mitochondrial alterations. In detail, rapamycin induces the expression of genes promoting mitophagy (PINK1, PARKIN, ULK1, AMBRA1) and mitochondrial fission (FIS1, DRP1). This occurs along with over-expression of VPS34, an early gene placed upstream in the autophagy pathway. The topographic stoichiometry of proteins coded by these genes within mitochondria indicates that, a remarkable polarization of proteins involved in fission and mitophagy within mitochondria including LC3 takes place. Co-localization of these proteins within mitochondria, persists for weeks following rapamycin, which produces long-lasting mitochondrial plasticity. Thus, rapamycin restores mitochondrial status in GBM cells. These findings add novel evidence about mitochondria and GBM, while fostering a novel therapeutic approach to restore healthy mitochondria through mTOR inhibition.
\end{abstract}

Keywords: OPA1; FIS1; DRP1; VPS34; ULK1; AMBRA1; PINK1; PARKIN; autophagy; mitochondria

\section{Introduction}

In glioblastoma multiforme (GBM), mTOR is activated and autophagy is inhibited [1]. This, in turn, inhibits cell differentiation and fosters proliferation of glioblastoma stem progenitor cells [2]. Autophagy suppression is documented by a decrease in LC3B-2 and beclin1, which is documented at gold-standard transmission electron microscopy (TEM) [3]. A chain of events exists, where suppressed autophagy fosters tumor progression, relapse, and radio-resistance [4]. When autophagy is restored, GBM cells differentiate [5,6]. Upregulation of mTORC1 determines autophagy suppression, which stimulate GBM cancer stem cells, as documented in glioblastoma cell lines, primary GBM cells cultures, and implanted GBM xenograft [5-10]. It is likely that a beneficial role of autophagy depends on the clearance of specific proteins, which sustain tumor progression, such as the prion protein PrPc, which promotes the growth of GBM [7,11]. A fascinating hypothesis 
suggests that other autophagy-dependent effects, including mitochondrial turnover, may be relevant in the natural course of GBM [11-16]. Thus, mitochondrial alterations and protein misfolding co-exist in GBM [13-19]. In fact, in a very recent study we documented a suppression of mitochondrial biogenesis, which was restored by rapamycin [10]. To encompass the knowledge of mitochondrial status in GBM cells in the present study we document mitochondrial fission, fusion, and mitophagy. The study was carried out in baseline conditions and at various time intervals following a short challenge with rapamycin. A quantitative analysis is carried out of both gene and protein expression by morphometric stoichiometry at mitochondrial level. Mitochondrial fission, and mitophagy were related to mitochondrial status. In fact, fission and mitophagy are expected to buffer cell damage generated by altered mitochondria [20-22]. This study wishes to add evidence on how specific alterations of mitophagy and mitochondrial status may be relevant for GBM malignancy $[13,14,16,23-33]$.

\section{Results}

2.1. Dose-Response and Time-Course of Rapamycin-Induced Mitochondrial Number and Alterations

These experiments were carried out by using various doses $(1 \mathrm{nM}, 10 \mathrm{nM}$, and $100 \mathrm{nM})$ and times $(12 \mathrm{~h}, 24 \mathrm{~h}$, and $72 \mathrm{~h})$ of rapamycin continuous exposure in order to assess which dose and time were most appropriate to assess the effects produced at various time intervals of rapamycin withdrawal. Thus, these pilot experiments were designed to select the dose and time of a short exposure to rapamycin, which were effective to modify persistently the mitochondrial status. As shown in Figure S1, $24 \mathrm{~h}$ exposure to $10 \mathrm{nM}$ rapamycin produces the highest number of healthy and functional mitochondria assessed with MitoTracker-Red (representative pictures of Figure S1A and graphs of Figure S1B) as well as the maximal number of total mitochondria and the lowest number of altered mitochondria counted at ultrastructural morphometry (Figures S2-S5). In fact, at 24 h of continuous $10 \mathrm{nM}$ rapamycin exposure mitochondria were in excess of $150 \%$ of controls. This dosing and timing reproduce previous published data, when the dose-response of rapamycin to stimulate mitochondrial biogenesis reached a plateau at $10 \mathrm{nM}$ rapamycin [10]. These experimental conditions were kept steady all over the study in order to measure changes taking a place at prolonged time intervals (up to $21 \mathrm{~d}$ ) of rapamycin withdrawal. This allowed to check the persistency of improved mitochondrial status produced by the long-lasting effects produced by rapamycin, even when rapamycin was no longer present.

\subsection{Long-Lasting Increase of Mitochondria and Clearance of Altered Mitochondria}

Following a short-time rapamycin exposure an increase of mitochondria was detected during rapamycin withdrawal. As shown in representative pictures, Figure $1 \mathrm{~A}$ mitochondria observed in controls become denser and smaller following rapamycin $10 \mathrm{nM}$. The increase in total mitochondria was remarkably steady from $1 \mathrm{~d}$ up to $21 \mathrm{~d}$ following a rapamycin challenge (10 $\mathrm{nM}$, for $24 \mathrm{~h}$ graph of Figure 1B), and it was concomitant with a long-lasting decrease in the number of altered mitochondria (graph of Figure 1C). The increase in total mitochondria also depend on newly synthesized mitochondria on mitochondrial biogenesis reported in Ferese et al. [10], which exceeds the decrease in the amount of altered organelles reported here. Again, an increased mitochondrial fission may contribute to this effect; therefore, such an issue will be specifically addressed later in the study. It is remarkable the long persistency of the effect which does not vanish even keeping the cells without rapamycin for $21 \mathrm{~d}$. This calls for a rapamycin-induced plasticity in determining mitochondrial status. 
A

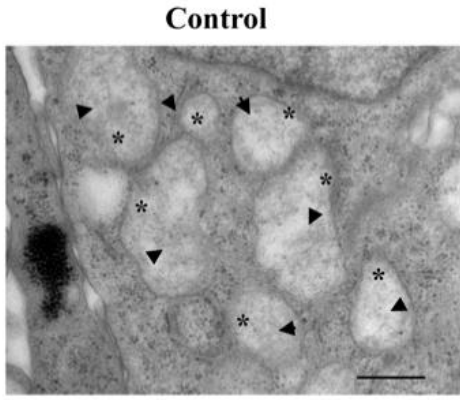

Rapamycin 7d

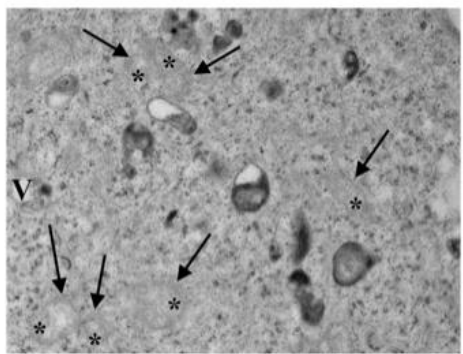

B

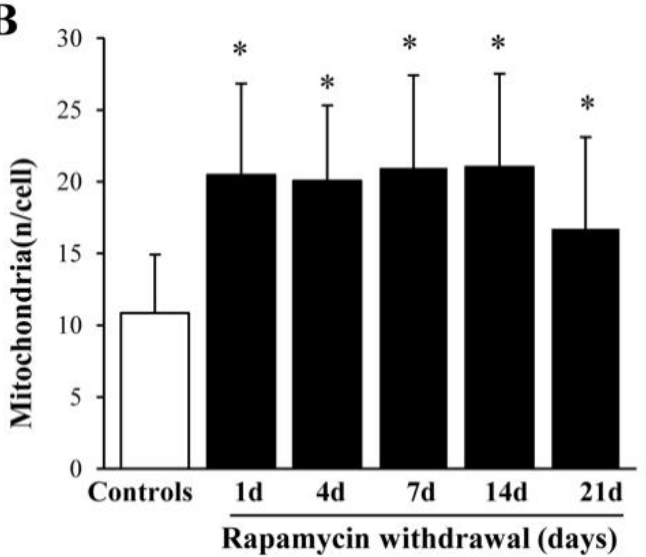

Rapamycin 1d

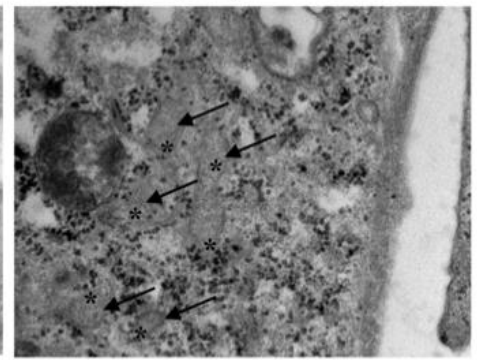

Rapamycin 14d

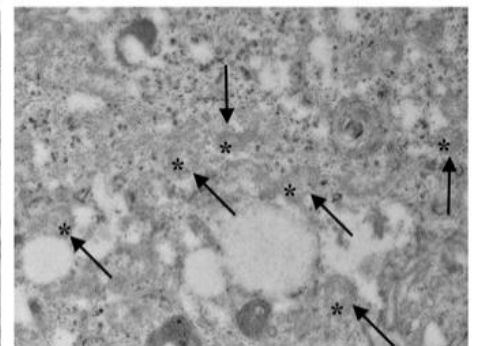

C

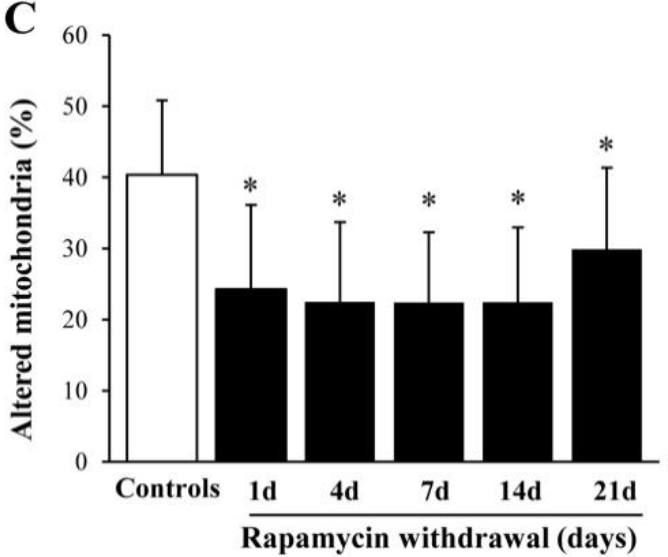

Figure 1. Rapamycin increases the number of mitochondria and reduces altered mitochondria time-dependently. (A) Representative pictures of mitochondria from controls and following different time of $10 \mathrm{nM}$ rapamycin withdrawal. Both normally structured, small (arrows), and altered, large mitochondria (arrowhead) are shown in these pictures. Graph (B) reports the total number of mitochondria per cell. Graph (C) reports the percentage of altered mitochondria. Counts represent the mean $\pm \mathrm{SD}$ from $\mathrm{N}=50$ cells per group. Asterisk $\left(^{*}\right)=$ mitochondria; $\mathrm{ER}=$ endoplasmic reticulum. ${ }^{*} p \leq 0.05$ compared with control. Scale bars $=1 \mu \mathrm{m}$.

\subsection{Rapamycin Increases the Histofluorescence from Healthy Mitochondria}

As expected, representative pictures of Figure 2 show a clear and steady increase in the fluorescent signal produced by the dye Mito-Tracker Red, which stains functional mitochondria [34]. Rapamycin-induced improvement of mitochondrial status persists up to $21 \mathrm{~d}$ following withdrawal (Figure 2A,B). This may depend on the transcription of specific genes.

\subsection{Rapamycin Increases Mitochondrial Fission Genes FIS1 and DRP1, While Decreases Fusion Gene OPA1}

As expected, rapamycin alters expression of genes related to mitochondrial dynamics. In fact, rapamycin increases the expression of genes related to mitochondrial fission (FIS1 and $D R P 1$, Figure $3 \mathrm{~A}, \mathrm{~B}$, respectively), while it decreases the gene OPA1 related to mitochondrial fusion. This is expected to contribute to the increase in mitochondrial number. 

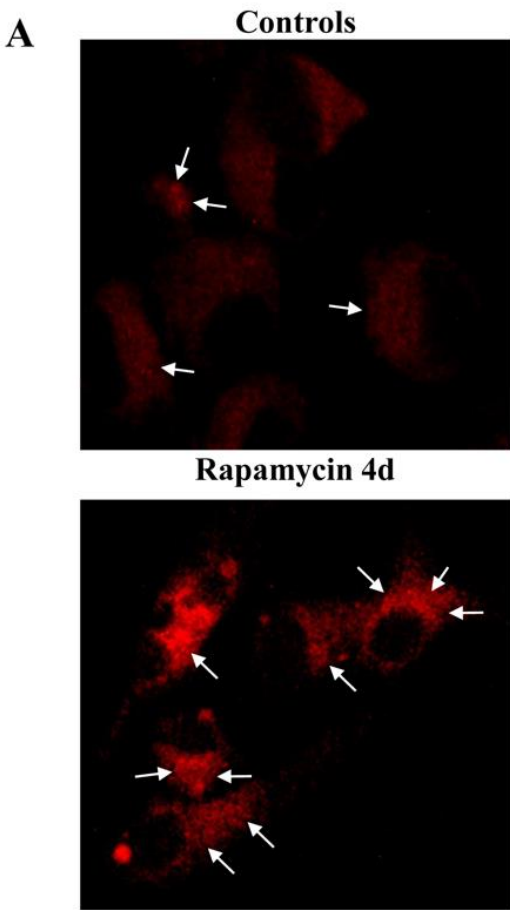

Rapamycin 14d

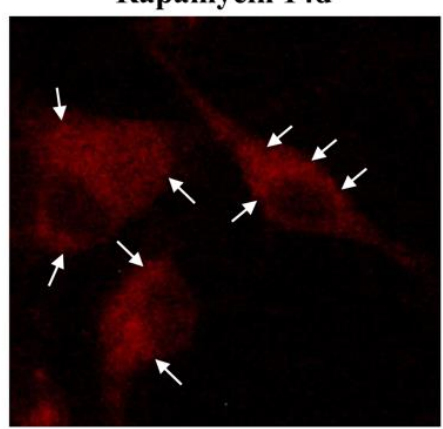

B

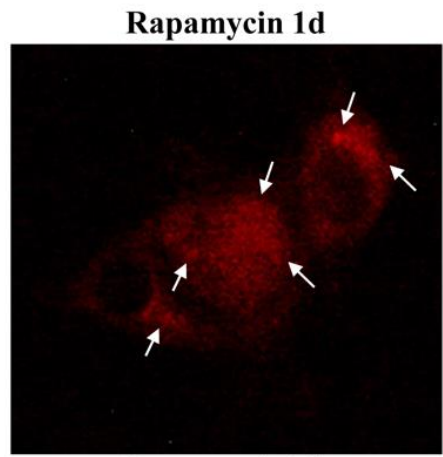

Rapamycin 7d

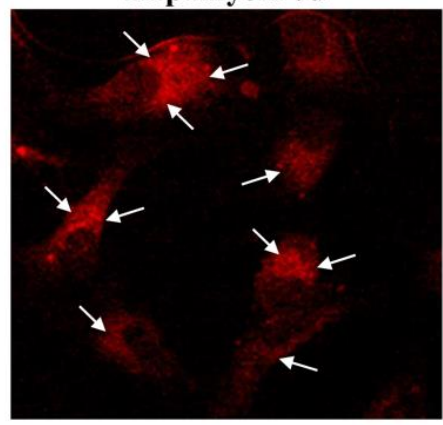

Rapamycin 21d
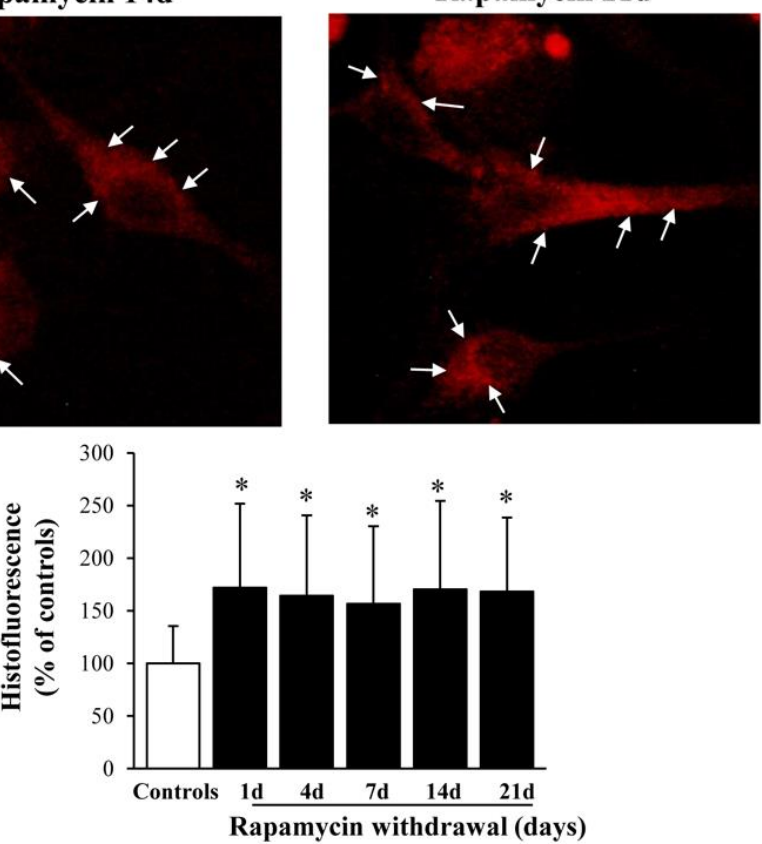

Figure 2. During rapamycin withdrawal a persistent increase in the amount of healthy mitochondria takes place. (A) Representative pictures stained with MTR showing healthy mitochondria (arrows) from controls or rapamycin $(10 \mathrm{nM}$ for $24 \mathrm{~h}$ ) at various time intervals following withdrawal (from $1 \mathrm{~d}$ up to $21 \mathrm{~d}$ ). It is evident how rapamycin treatment produces increased fluorescence, which is steady at various time intervals. This is counted in the graph (B), which reports the percentage of MTR histofluorescence compared with control, which persists steadily elevated up to $21 \mathrm{~d}$. Counts represent the mean $\pm \mathrm{SD}$ from $\mathrm{N}=50$ cells per group. $* p \leq 0.05$ compared with control. Scale Bar $=20 \mu \mathrm{m}$. 
$\mathbf{A}$

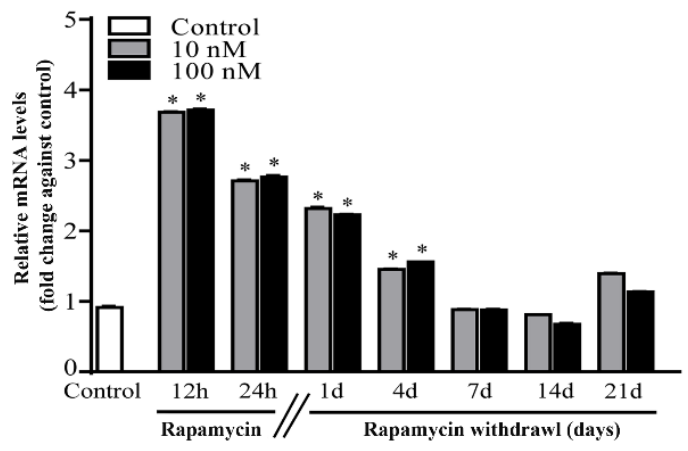

B
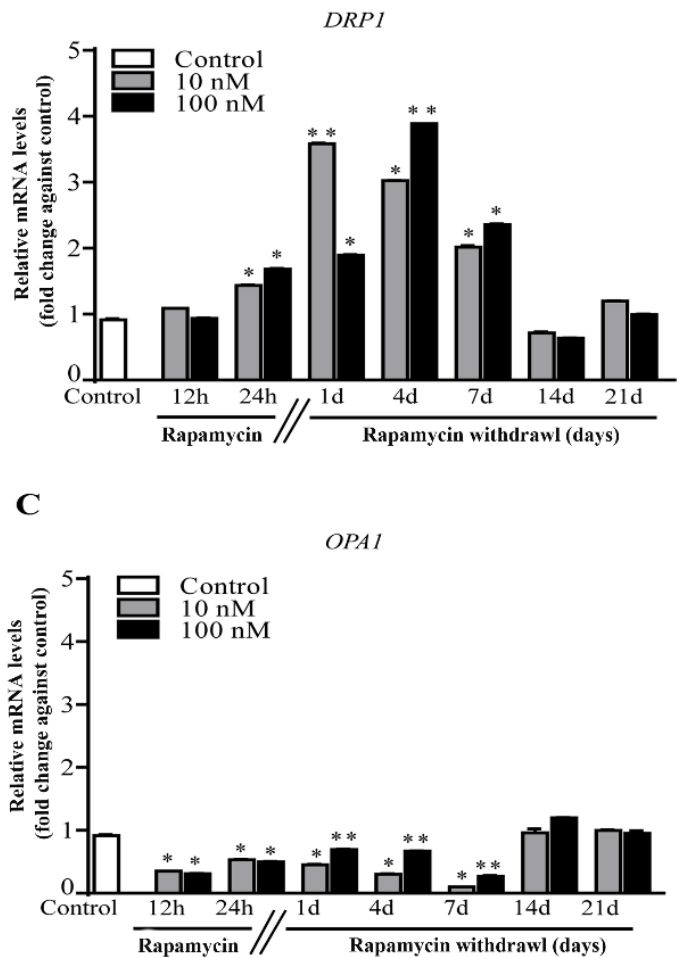

Figure 3. Effects of rapamycin on fission and fusion genes. RT-PCR for (A) FIS1, (B) DRP1, (C) OPA1. The fission-related genes FIS1 and DRP1 were both increased by rapamycin, with an earlier increase concerning FIS1, which reached back control levels at 7 days. DRP1 increased later reaching back control levels at 14 days. The fusion antigen OPA1 decreased following both a low and high dose of rapamycin and ruse back to control levels at 14 days. Counts represent the mean $\pm \mathrm{SD}$. ${ }^{*} p \leq 0.05$ compared with control. ${ }^{* *} p \leq 0.05$ compared with control and $10 \mathrm{nM}$ rapamycin.

\subsection{Rapamycin Differently Alters the Autophagy Genes VPS34, ULK1 and AMBRA1}

Rapamycin persistently increases (for $7 \mathrm{~d}$ of rapamycin withdrawal) in excess of threefold the VPS34 gene, which is upstream in the autophagy cascade (Figure 4A). This overlaps with the specific mitophagy gene ULK1 (Figure 4B). It is remarkable that, both genes being overexpressed, undergo a short transient inhibition at $1 \mathrm{~d}$ of rapamycin withdrawal (Figure $4 \mathrm{~A}, \mathrm{~B})$. Contrary wise, the levels of the mitophagy gene $A M B R A 1$, were different at $10 \mathrm{nM}$ and $100 \mathrm{nM}$ of rapamycin (Figure 4C). In fact, at $10 \mathrm{nM}$ rapamycin $A M B R A 1$ was not significantly affected, whereas at the highest dose $(100 \mathrm{nM})$ rapamycin, significantly decreased $A M B R A 1$ compared with control. This might be due to the fact that $A M B R A 1$, plays a complex role in mitophagy since depending on the amount of phosphorylation it might up- or down-regulate ULK1, thus increasing or suppressing mitophagy $[35,36]$. 
$\mathbf{A}$

VPS34

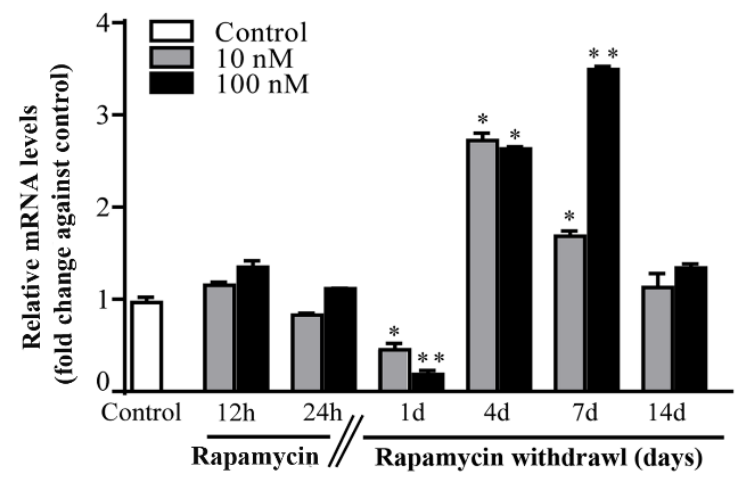

$\mathbf{B}$

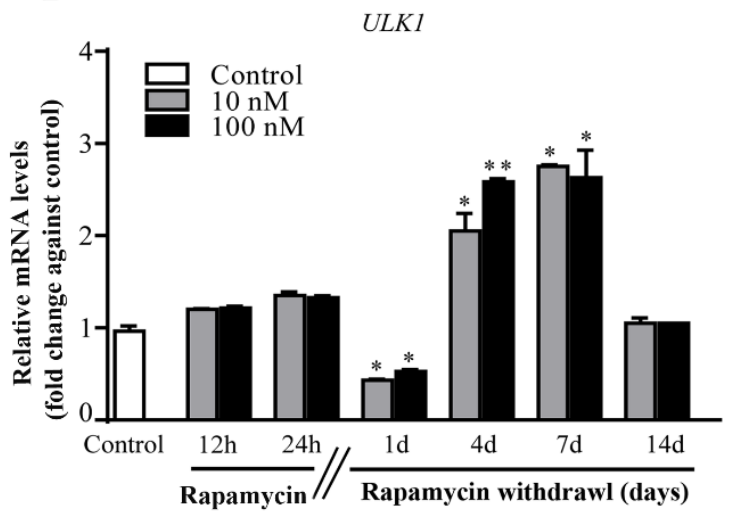

C

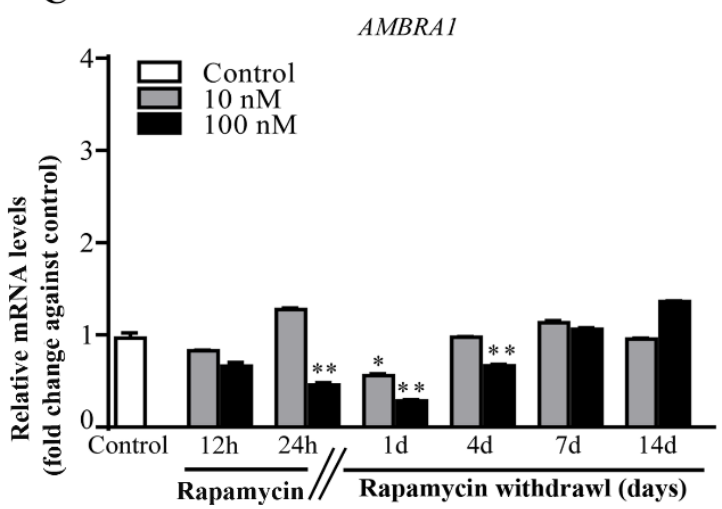

Figure 4. Rapamycin increases the mitophagy genes VPS34 and ULK1 while decreases AMBRA1. RT-PCR for (A) VPS34, (B) ULK1, (C) AMBRA1. In detail, VPS34 and ULK1 were depressed compared with controls a $1 \mathrm{~d}$ following rapamycin (both $10 \mathrm{nM}$ and $100 \mathrm{nM}$ ) withdrawal. Later on, a marked increase in both genes was measured at $4 \mathrm{~d}$ and $7 \mathrm{~d}$, going back to control levels at $14 \mathrm{~d}$. In contrast, AMBRA1 never increased compared with controls. In detail, as occurring for VPS34 and ULK1, $A M B R A 1$ decreases at $1 \mathrm{~d}$ following rapamycin (both $10 \mathrm{nM}$ and $100 \mathrm{nM}$ ) withdrawal. Such a decrease was evident also during rapamycin administration and at $4 \mathrm{~d}$ of withdrawal, when the highest dose $(100 \mathrm{nM})$ of rapamycin was administered. Counts represent the mean $\pm \mathrm{SD} .{ }^{*} p \leq 0.05$ compared with control. ${ }^{* *} p \leq 0.05$ compared with control and $10 \mathrm{nM}$ rapamycin.

\subsection{Rapamycin Withdrawal Modulates PINK1 and PARKIN Genes}

Despite decreased level (PINK1 Figure 5A) or increased amount (PARKIN Figure 5B) were detected during, or short after rapamycin exposure, a marked decrease in PARKIN expression was observed at $4 \mathrm{~d}$ during rapamycin withdrawal (Figure 5B). This effect 
markedly contrasts with the specific over expression of mitophagy-related genes and suggests a different regulation in the expression of genes related to mitochondrial removal (consider here also the discrepancy described for AMBRA1 compared with ULK1). Thus, increased expression of PARKIN seems to be required for a short time in order to trigger the mitophagy process. Similarly, the amount of PINK1 changes transiently following rapamycin (Figure 5A).

A

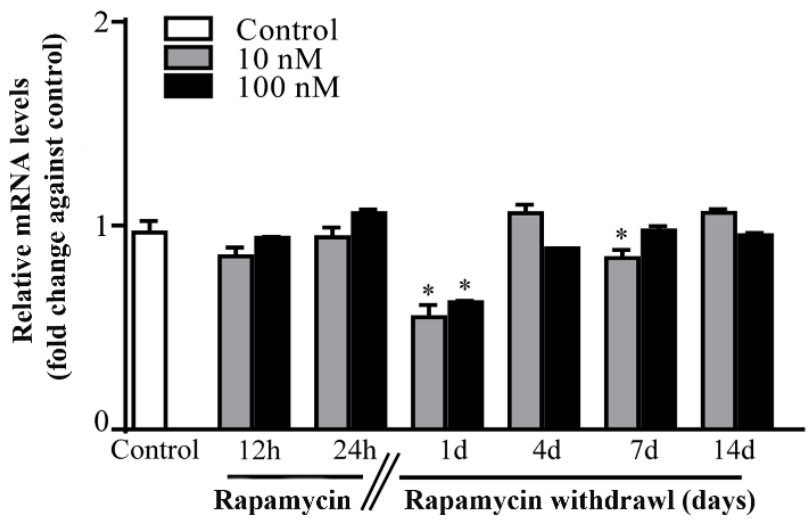

B

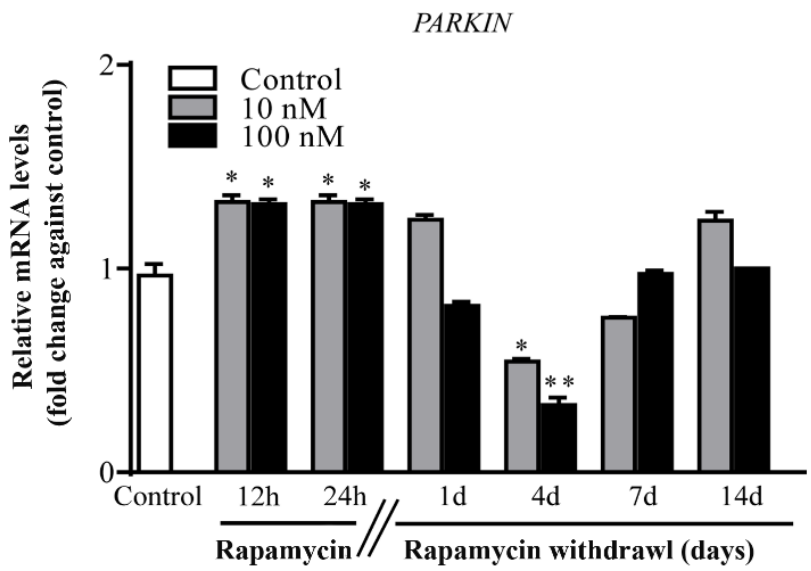

Figure 5. Rapamycin transiently modifies expression of PINK1 and PARKIN. RT-PCR for (A) PINK1 and (B) PARKIN. PINK1 never increases following rapamycin. This gene undergoes a decrease following $1 \mathrm{~d}$ of rapamycin (10 $\mathrm{nM}$ and $100 \mathrm{nM}$ withdrawal), with a slight decrease also measured at $7 \mathrm{~d}$ following the lowest dose. In contrast, PARKIN rose early on during rapamycin (both doses) administration and similarly to PINK1 decreased transiently at $4 \mathrm{~d}$ following both doses of rapamycin. Counts represent the mean $\pm \mathrm{SD}$. ${ }^{*} p \leq 0.05$ compared with control. ${ }^{* *} p \leq 0.05$ compared with control and $10 \mathrm{nM}$ rapamycin.

\subsection{Rapamycin Polarizes Increased LC3 within Mitochondria}

Despite being roughly increased in the cell, a specific compartmentalization of LC3 following rapamycin was measured at mitochondrial level (Figure 6). This is quite consistent with the persistency of rapamycin-induced increase in autophagy as evidenced by VPS34 up to $14 \mathrm{~d}$ (graph Figure S6A). Nonetheless, while LC3 possesses a mitochondrial polarization, VPS34 does not show such a preferential topography (graphs of Figure S6B-D), which suggests a rather generalized and upstream signal for autophagy for VPS34 compared with LC3 which best targets specific compartment to be digested [3]. 
A

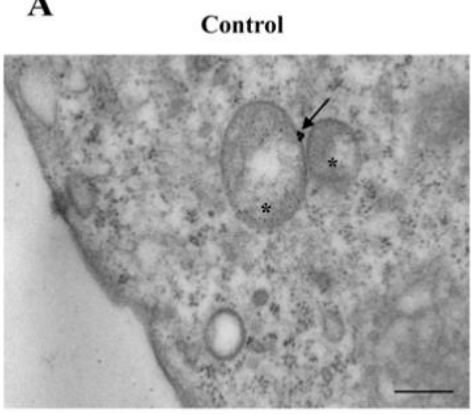

B

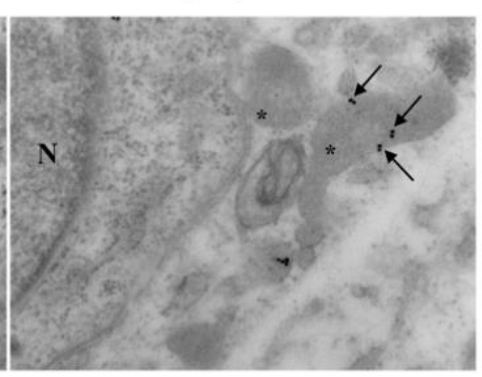

C

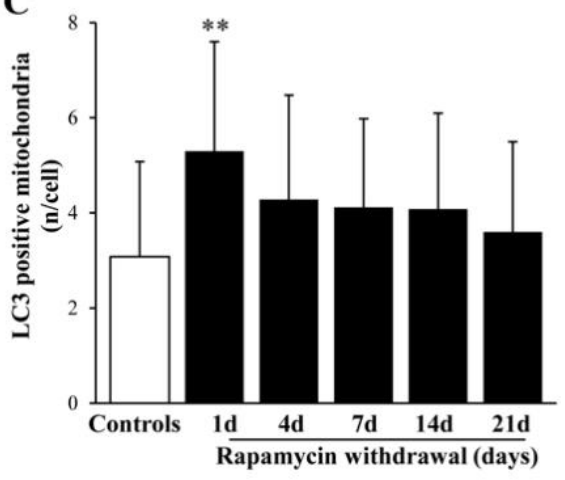

F
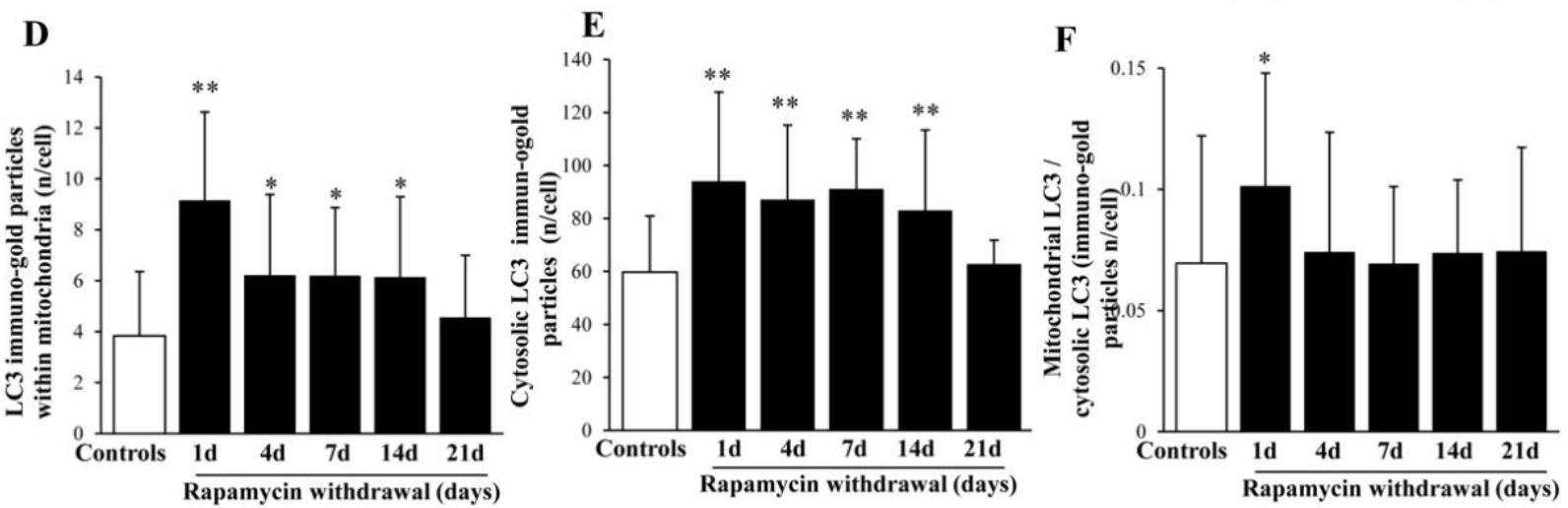

Figure 6. Rapamycin increases the amount of LC3-positive mitochondria. Representative TEM micrograph showing LC3-positive mitochondria from control (A) and following $1 \mathrm{~d}$ rapamycin withdrawal (B). Arrows point to LC3 immunogold particles within mitochondria. Graphs report the LC3-positive mitochondria (C), LC3 immuno-gold particles within mitochondria (D), the cytosolic amount of LC3 (E), and the ratio of mitochondrial to cytosolic LC3 particles (F). Counts represent the mean $\pm \mathrm{SD}$ from $\mathrm{N}=50$ cells per group. ${ }^{*} p \leq 0.05$ compared with control. ${ }^{* *} p \leq 0.05$ compared with controls and $21 \mathrm{~d}$. Scale Bar $=0.5 \mu \mathrm{m}$, Asterisk $\left(^{*}\right)=$ mitochondria, $\mathrm{N}=$ nucleus.

It is well known that rapamycin increases LC3 in the cell and within ATG vacuoles. The present study adds evidence for a powerful compartmentalization of LC3 towards mitochondria exerted by rapamycin. As shown in representative Figure 6A,B, at $1 \mathrm{~d}$ following rapamycin $10 \mathrm{nM}$ withdrawal, LC3 is evident at the mitochondrial level. In detail, the amount of mitochondria staining with LC3 increases almost twofold of control (Figure $6 \mathrm{~B}, \mathrm{C}$ ). Such a finding is more evident when counting the number of LC3 particles within mitochondria (Figure 6D). This is compatible with the classic increase of cytosolic LC3 induced by rapamycin and confirmed here in Figure 6E. Nonetheless when plotting the increase of LC3 particles within mitochondria vs. cytosolic LC3, the effects of rapamycin was more powerful to address LC3 within mitochondria rather than towards stochastic cytosolic areas (Figure 6F). In these graphs, another phenomenon is apparent, which concerns the persistency of high LC3 levels, which vanishes at $14 \mathrm{~d}$ both within mitochondria and cytosol. The graph shows a significant compartmentalization of LC3 at mitochondrial level, such a placement of LC3 particles counted at immuno-gold stoichiometry is comparable to the compartmentalization of LC3 within ATG vacuoles. This makes mitochondria as a key site for LC3 and confirms the concerted pattern of mitophagy in the autophagy process [10].

\subsection{Rapamycin Increases Mitophagy-Related Proteins within Mitochondria}

Similar to LC3, though more evident, is the polarization of ULK1 immuno-gold within mitochondria (representative Figure $7 \mathrm{~A}, \mathrm{~B}$ and graphs of Figure $7 \mathrm{C}, \mathrm{D})$. Indeed, the increase of ULK1 within mitochondria surpasses, at large, the increase of ULK1 within cytosol (as counted in the graphs of Figure 7E,F). Remarkably, such a polarization is evident also for AMBRA1 (representative pictures at Figure 8A,B). In fact, the stoichiometric count of AMBRA1-stained mitochondria (graph of Figure $8 \mathrm{C}$ ) and the amount of the protein AM- 
BRA1 within mitochondria (Figure 8D), indicate a selective increase within mitochondria compared with a slight decrease in the cytosol (Figure 8E), which leads to the highest mitochondria/cytosol ratio for AMBRA1 compared with other mitophagy protein (Figure 8F). This is consistent with the powerful effects induced by mitophagy stimulation through the interaction of AMBRA1 with LC3 [37-39]. In the context of targeting mitochondrial removal, the placement of PARKIN within mitochondria is key to form a complex with PINK1 which triggers mitophagy $[39,40]$. In the present study, it is shown that, expression of the PARKIN protein is suddenly increased by rapamycin (Representative Figure 9A,B), thus focusing its effects at the mitochondrial level (Figure 9C,D). This occurs despite a generalized increase of PARKIN in the cytosol (Figure 9E), though occurring to a lesser extent, as shown by the mitochondrial vs. cytosolic ratio of PARKIN immuno-gold (Figure 9F). When comparing the increase of PARKIN compared with ULK1 and AMBRA1 it is remarkable that mitochondrial polarization of PARKIN occurs maximally shortly after the rapamycin challenge.
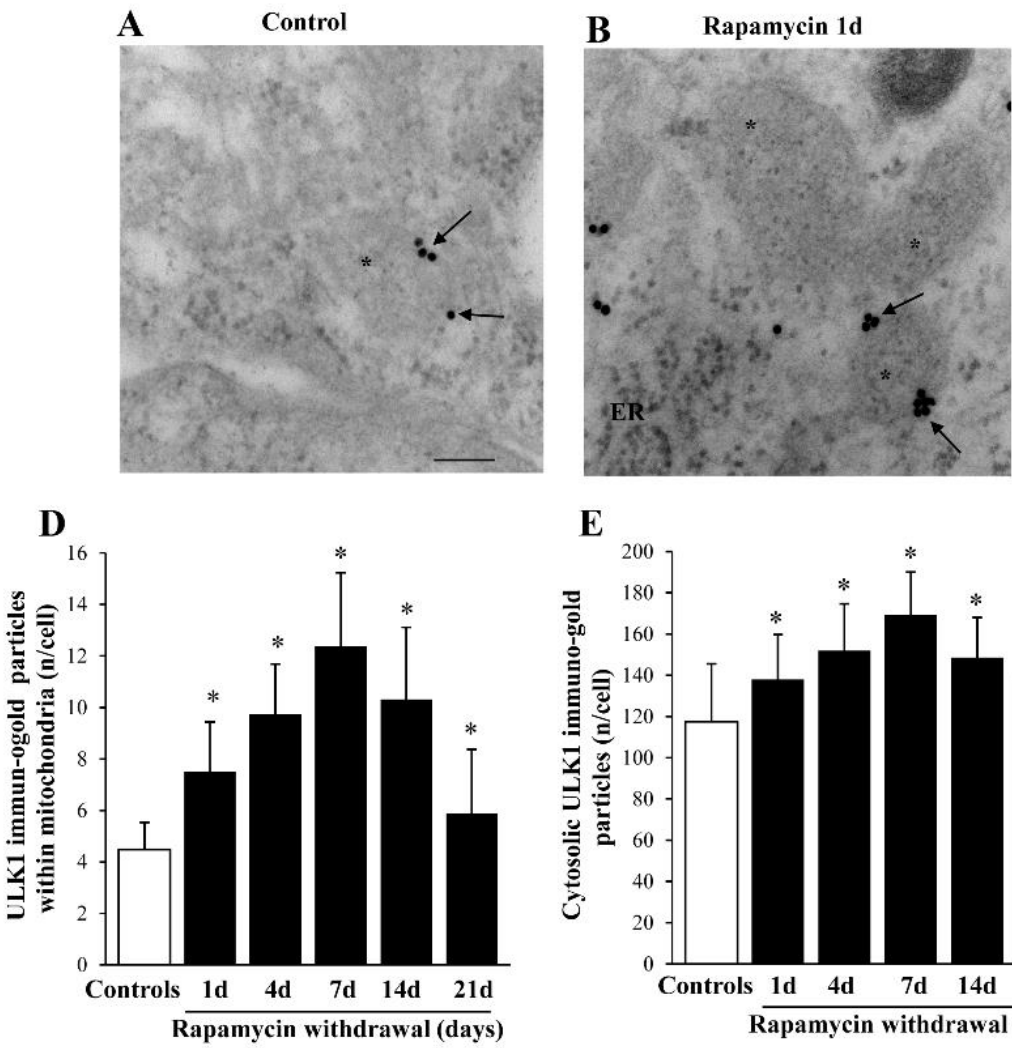

\section{E}

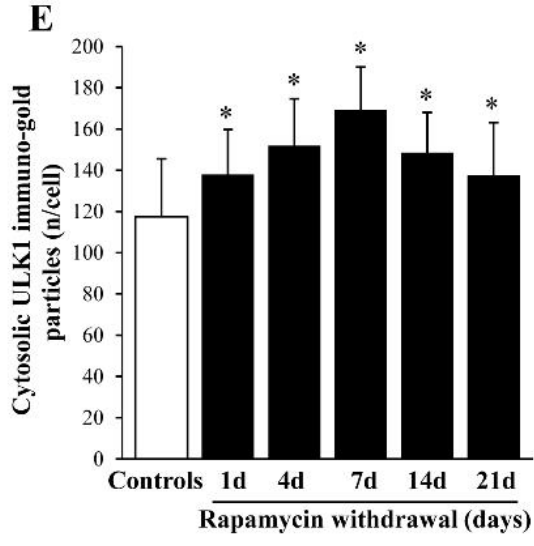

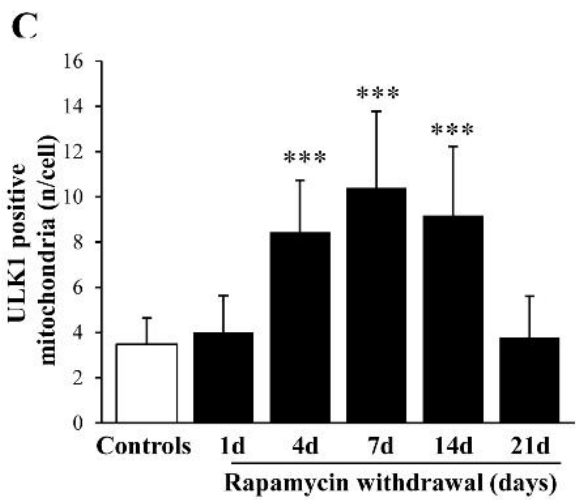

$\mathbf{F}$

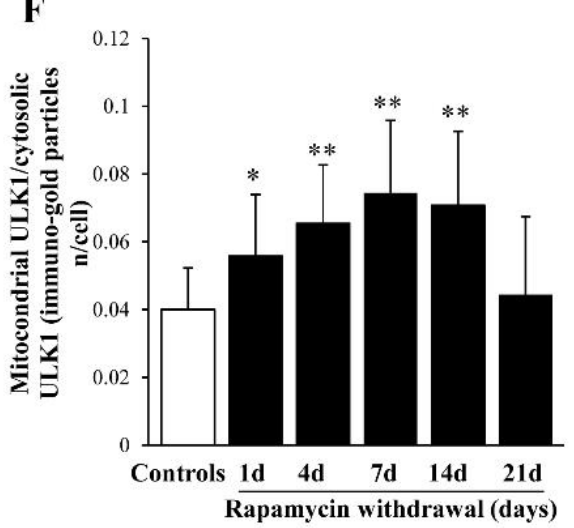

Figure 7. Representative immuno-gold and polarization graphs for the mitophagy marker ULK1. Representative TEM micrograph showing ULK1-positive mitochondria from control (A) and following $1 \mathrm{~d}$ rapamycin withdrawal (B). Arrows point to ULK1 immuno-gold particles within mitochondria. Graphs report the ULK1-positive mitochondria (C), ULK1 immuno-gold particles within mitochondria (D), the cytosolic amount of ULK1 (E), and the ratio of mitochondrial to cytosolic ULK1 particles (F). Values reported in the graph correspond to the mean $\pm \mathrm{SD}$. Mitochondria were counted in 50 cells per group. ${ }^{*} p \leq 0.05$ compared with controls. ${ }^{* *} p \leq 0.05$ compared with controls and $21 \mathrm{~d}$. ${ }^{* *} p \leq 0.05$ compared with controls, $1 \mathrm{~d}$ and $21 \mathrm{~d}$. Scale Bar $=0.2 \mu \mathrm{m}$, Asterisk $\left(^{*}\right)=$ mitochondria, ER = endoplasmic reticulum.

This suggests that PARKIN plays a key role in initiating the mitophagy process despite persisting for a very long time (at least 21 days). Such an effect is mirrored by its molecular partner PINK1 (representative pictures at Figure 10A,B), which persists elevated for at least $21 \mathrm{~d}$, albeit, selectively at mitochondrial level (graph of Figure 10C,D). In fact, in the cytosol there is noticeable increase in PINK1 at any time interval (Figure 10E), with a marked ratio between mitochondria and cytosol (Figure 10F). Such an effect resembles what described for AMBRA1, which is consistent with the canonical pathway of mitophagy. This happens 
though PINK1 phosphorylation at mitochondrial level, which makes it able to recruit and interact with PARKIN to promote mitochondrial removal [41].

A

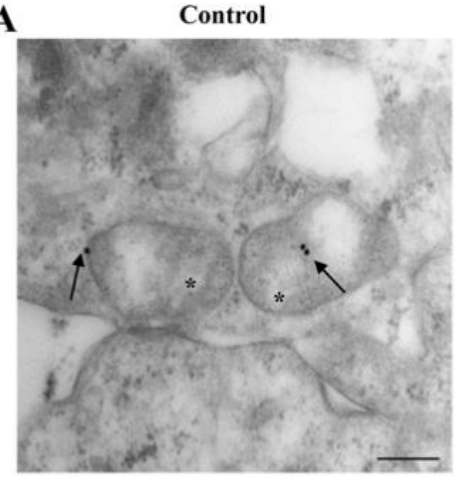

B

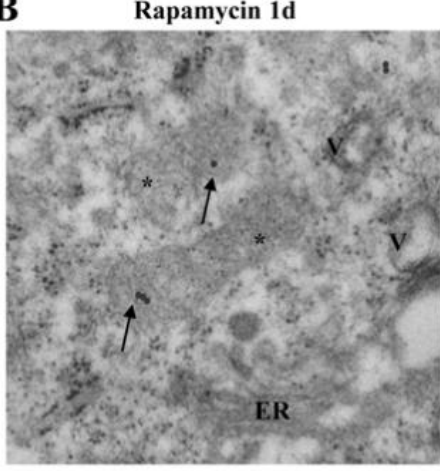

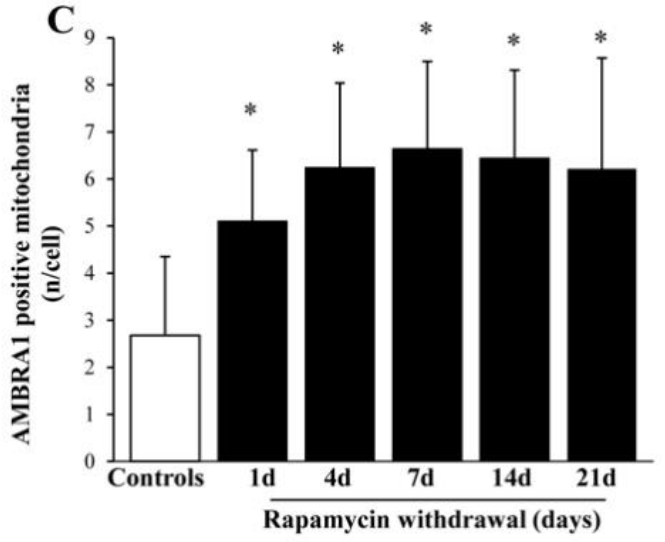

$\mathbf{F}$
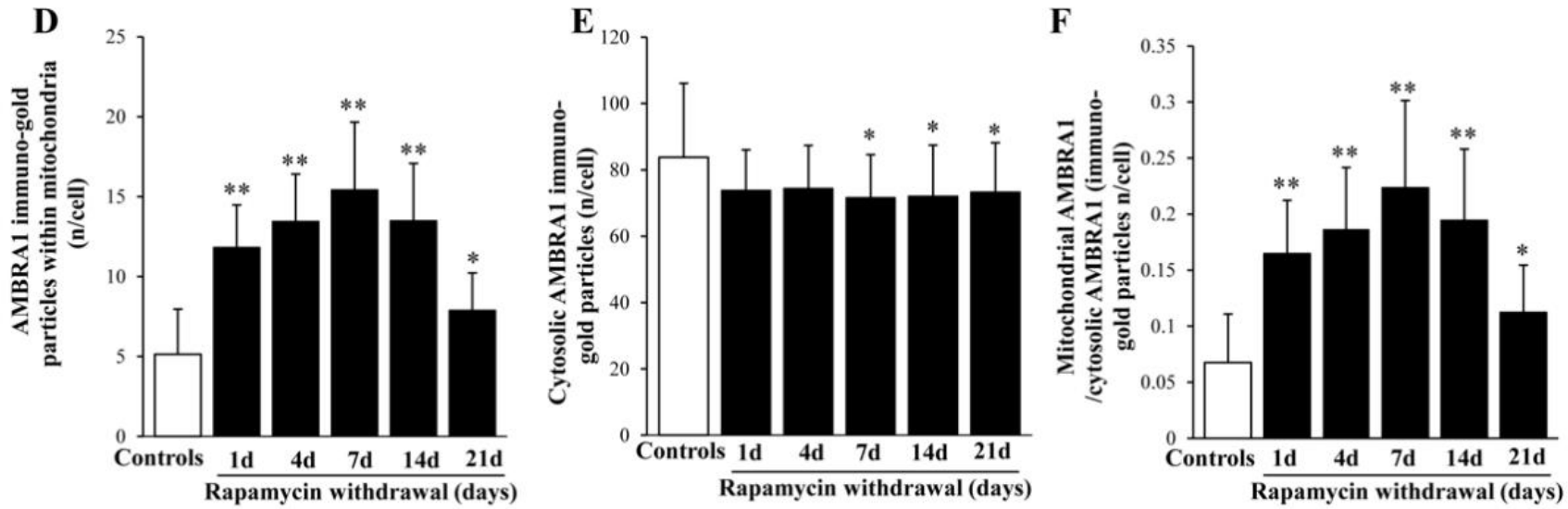

Figure 8. Representative immuno-gold and polarization graphs for the mitophagy marker AMBRA1. Representative TEM micrograph showing AMBRA1-positive mitochondria from control (A) and following $1 \mathrm{~d}$ rapamycin withdrawal (B). Arrows point to AMBRA1 immuno-gold particles within mitochondria. Graphs report the AMBRA1-positive mitochondria (C), AMBRA1 immuno-gold particles within mitochondria (D), the cytosolic amount of AMBRA1 (E), and the ratio of mitochondrial to cytosolic AMBRA1 particles (F). Values reported in the graph correspond to the mean \pm SD. Mitochondria were counted in 50 cells per group. ${ }^{*} p \leq 0.05$ compared with controls. ${ }^{* *} p \leq 0.05$ compared with controls and $21 \mathrm{~d}$. Scale Bar $=0.5 \mu \mathrm{m}$, Asterisk $\left({ }^{*}\right)=$ mitochondria, $\mathrm{ER}=$ endoplasmic reticulum.

A

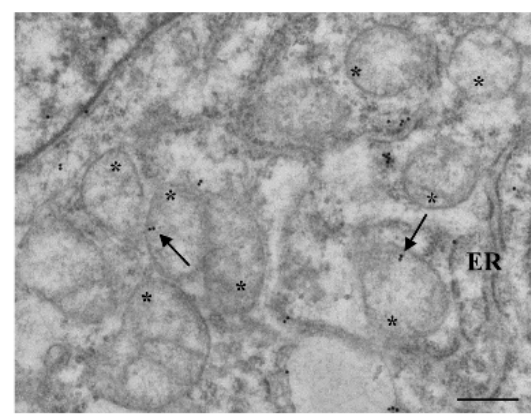

B

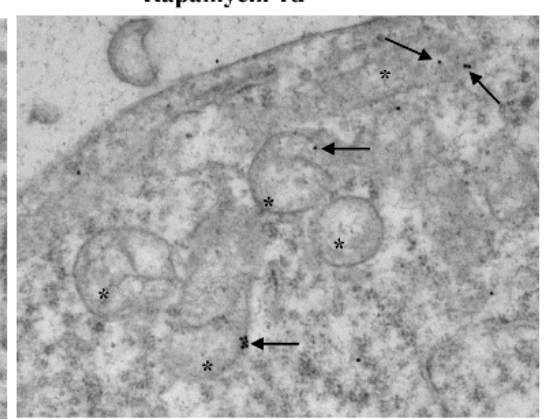

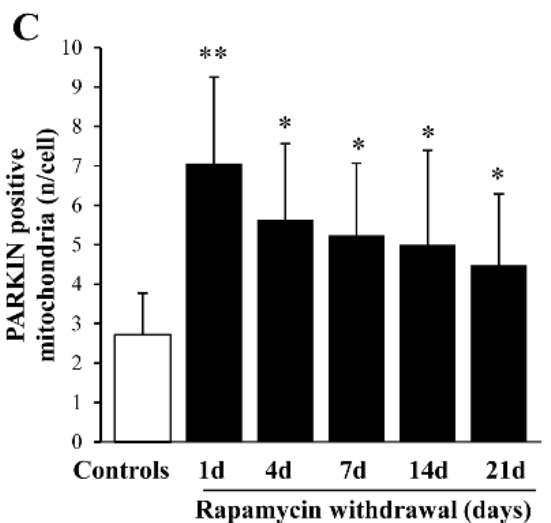

Figure 9. Cont. 

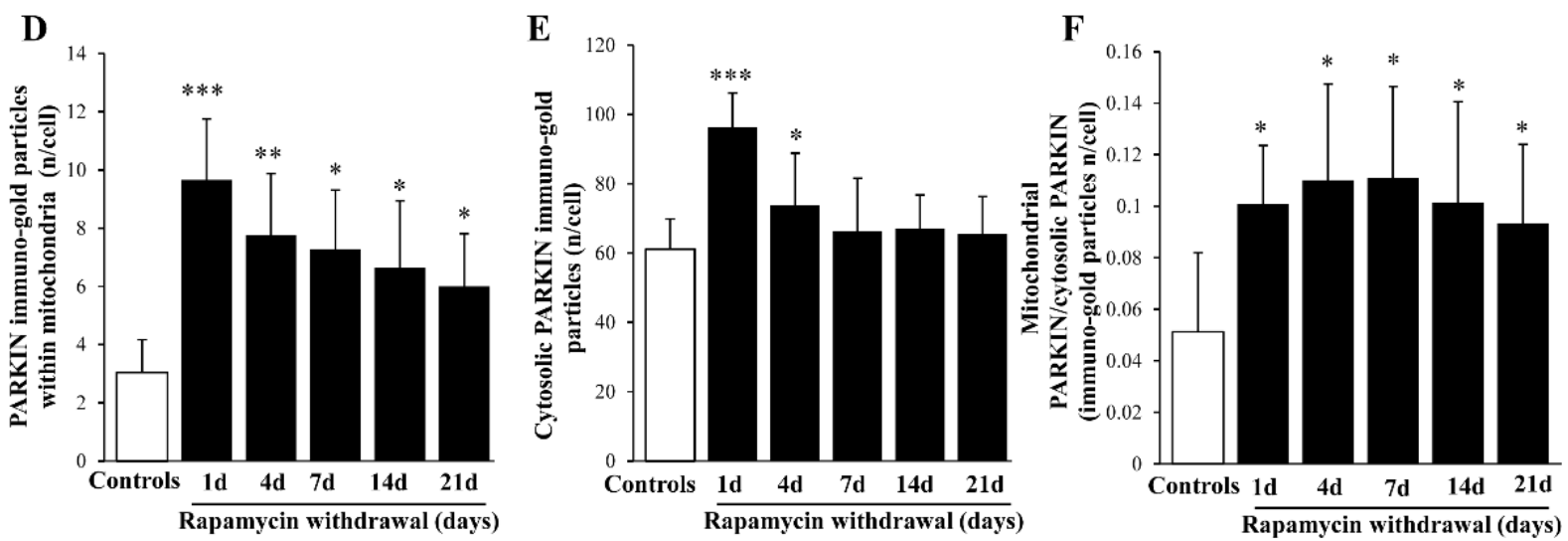

Figure 9. Representative immuno-gold and polarization graphs for PARKIN. Representative TEM micrograph showing PARKIN-positive mitochondria from control (A) and following $1 \mathrm{~d}$ rapamycin withdrawal (B). Arrows point to PARKIN immuno-gold particles within mitochondria. Graphs report the PARKIN-positive mitochondria (C), PARKIN immuno-gold particles within mitochondria (D), the cytosolic amount of PARKIN (E), and the ratio of mitochondrial to cytosolic PARKIN particles $(\mathbf{F})$. Values reported in the graph correspond to the mean \pm SD. Mitochondria were counted in 50 cells per group. ${ }^{*} p \leq 0.05$ compared with controls. ${ }^{* *} p \leq 0.05$ compared with controls and $21 \mathrm{~d}$. ${ }^{* *} p \leq 0.05$ compared with other groups. Scale Bar $=0.5 \mu \mathrm{m}$, Asterisk $\left(^{*}\right)=$ mitochondria, $\mathrm{ER}=$ endoplasmic reticulum.

A

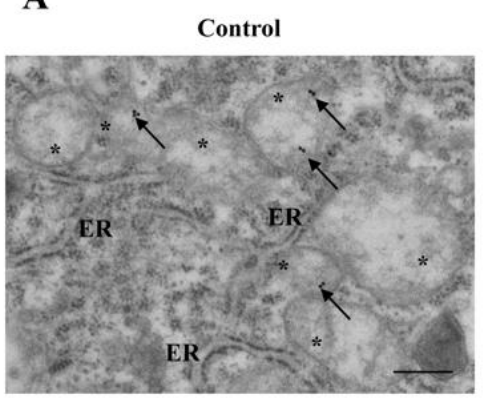

D

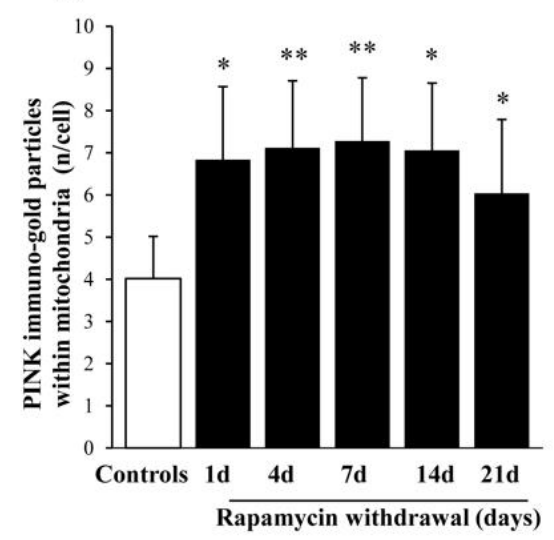

B

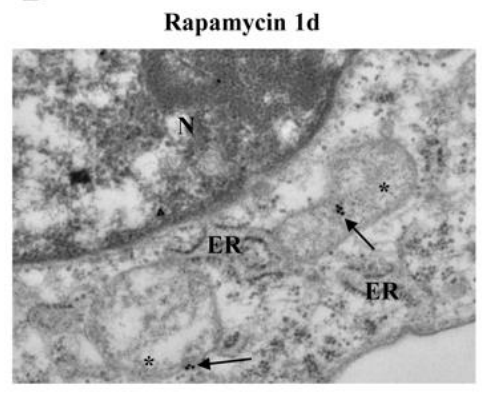

E

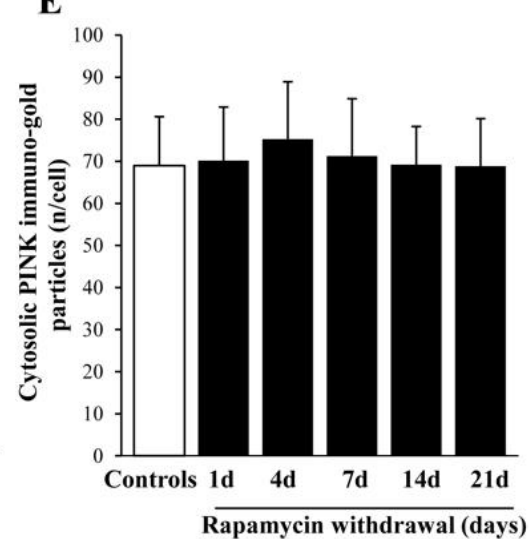

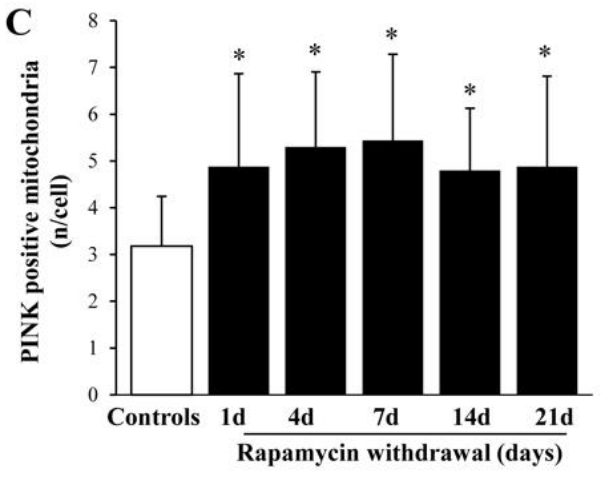

$\mathbf{F}$

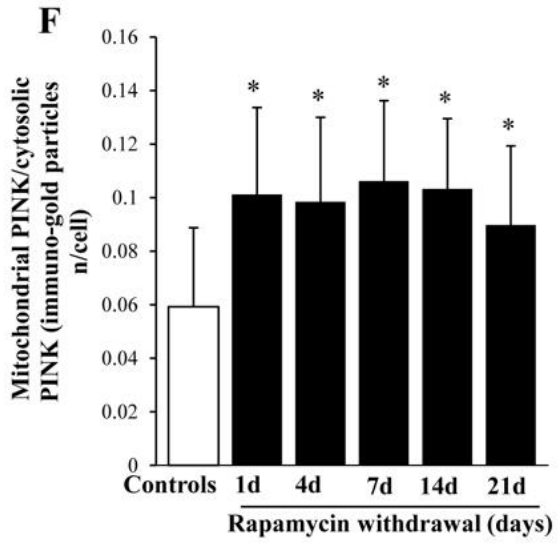

Figure 10. Representative immuno-gold and polarization graphs for PINK1. Representative TEM micrograph showing PINK1-positive mitochondria from control (A) and following $1 \mathrm{~d}$ rapamycin withdrawal (B). Arrows point to PINK1 immuno-gold particles within mitochondria. Graphs report the PINK1-positive mitochondria (C), PINK1 immunogold particles within mitochondria (D), the cytosolic amount of PINK1 (E), and the ratio of mitochondrial to cytosolic PINK1 particles (F). Values reported in the graph correspond to the mean $\pm \mathrm{SD}$. Mitochondria were counted in 50 cells per group. ${ }^{*} p \leq 0.05$ compared with controls. ${ }^{* *} p \leq 0.05$ compared with controls and $21 \mathrm{~d}$. Scale Bar $=0.5 \mu \mathrm{m}$, Asterisk $\left(^{*}\right)=$ mitochondria, $\mathrm{ER}=$ endoplasmic reticulum, $\mathrm{N}=$ nucleus. 


\subsection{Within Mitochondria, Rapamycin Increases the Fission Proteins FIS1 and DRP1, While the Fusion Protein OPA1 Is not Changed}

The fission marker FIS1 increases at all time intervals under analysis (Figure 11A,B) persistingly elevated at $14 \mathrm{~d}$ of rapamycin withdrawal. Within mitochondria FIS1 undergoes an increase, which also occurs in the cytosol (Figure 11C,F). Similarly, the fission antigen DRP1 augments following rapamycin (representative Figures 12A and 13B). However, differing from FIS1, DRP1 increases more focally within mitochondria (Figure 12C,D), compared with cytosol (Figure 12E). When immuno-gold for FIS1 and DRP1 were combined, the co-staining at mitochondrial level, was remarkable and persisted for $21 \mathrm{~d}$. This combined staining provides information on the interaction of FIS1 and DRP1. This is needed to promote mitochondrial fission as shown in a representative picture of a mitochondrial fission of Figure 13A and reported in graph of Figure 13B. In contrast, OPA1 level were neither altered nor significantly compartmentalized at early or mean time intervals (graphs of Figure 14A-C). Only a late increase in the ratio between mitochondrial and cytosolic OPA1 was detected (graph of Figure 14D). This is likely to depend on the switch in the fission/fusion cycle, where fusion rebounds after a binging of fission [42-44], when abundant mitochondria persist for weeks in the cell and may need to merge as shown in representative picture showing mitochondrial fusion in Figure 14E.

A
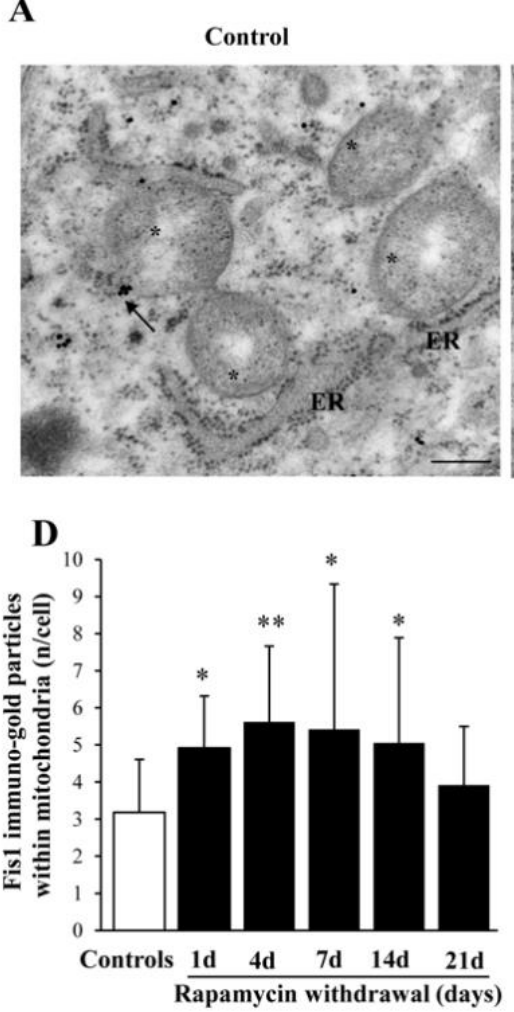

B

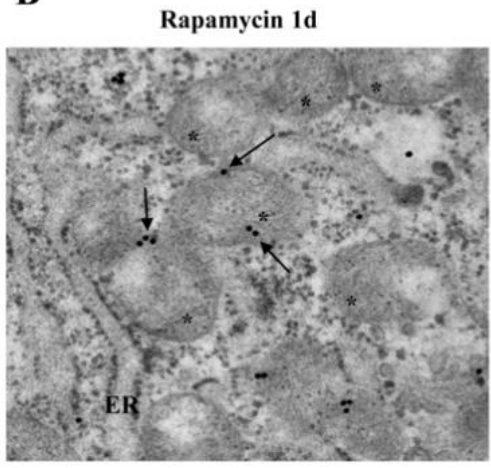

$\mathbf{E}$

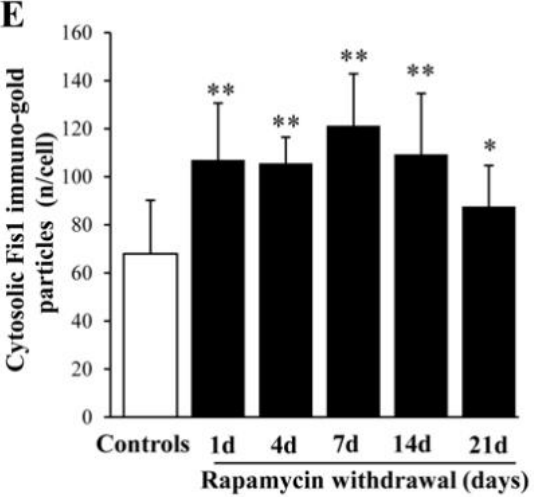

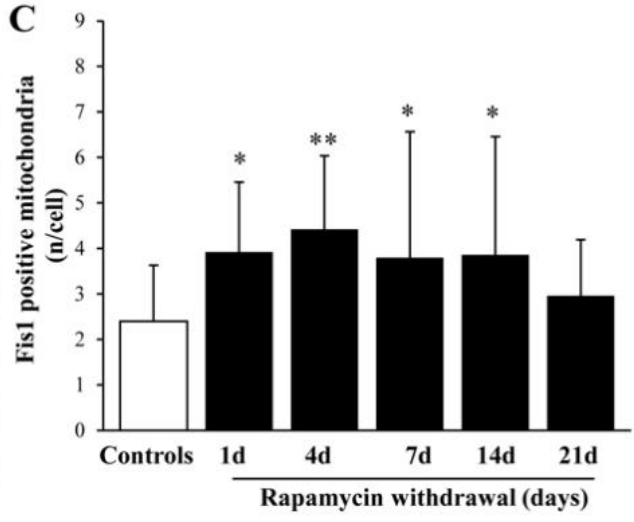

$\mathbf{F}$

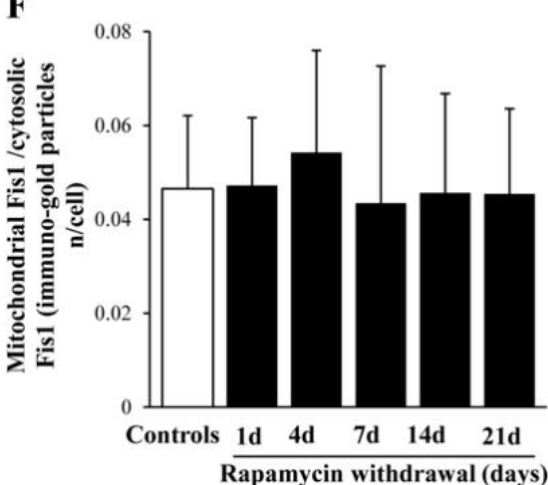

Figure 11. Representative immuno-gold and polarization graphs for the mitochondrial fission marker FIS1. Representative TEM micrograph showing FIS1-positive mitochondria from control (A) and following $1 \mathrm{~d}$ rapamycin withdrawal (B). Arrows point to FIS1 immuno-gold particles within mitochondria. Graphs report the FIS1-positive mitochondria (C), FIS1 immuno-gold particles within mitochondria (D), the cytosolic amount of FIS1 (E), and the ratio of mitochondrial to cytosolic FIS1 particles (F). Values reported in the graph correspond to the mean $\pm \mathrm{SD}$. Mitochondria were counted in 50 cells per group. ${ }^{*} p \leq 0.05$ compared with controls. ${ }^{* *} p \leq 0.05$ compared with controls and $21 \mathrm{~d}$. Scale Bar $=0.5 \mu \mathrm{m}$, Asterisk $(*)=$ mitochondria, $\mathrm{ER}=$ endoplasmic reticulum. 

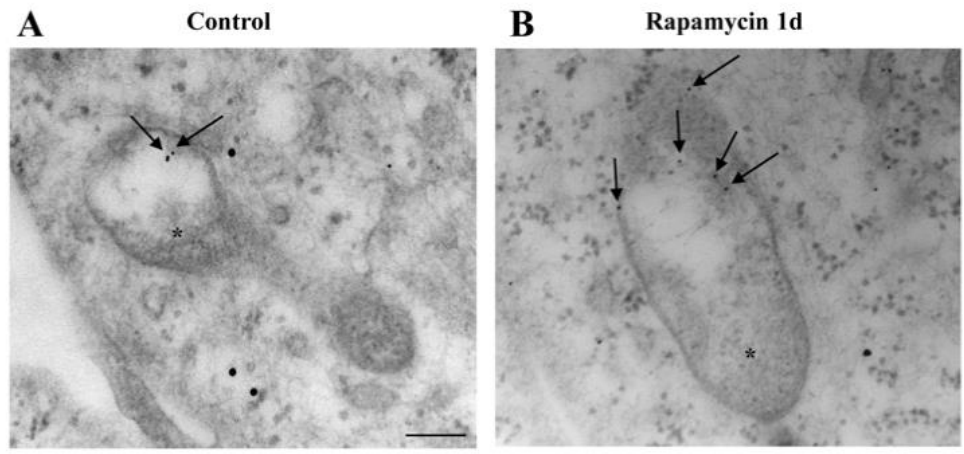

$\mathbf{E}$

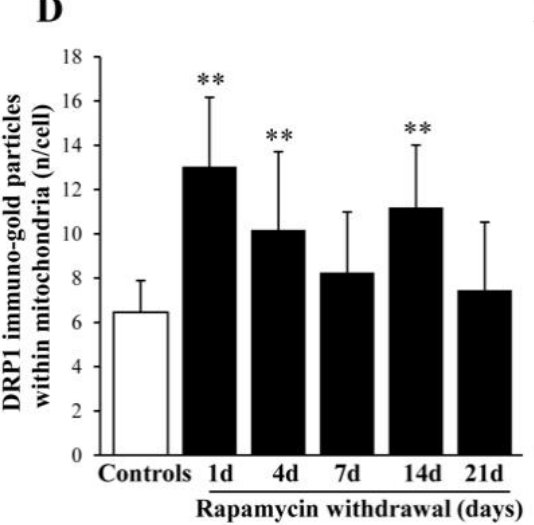

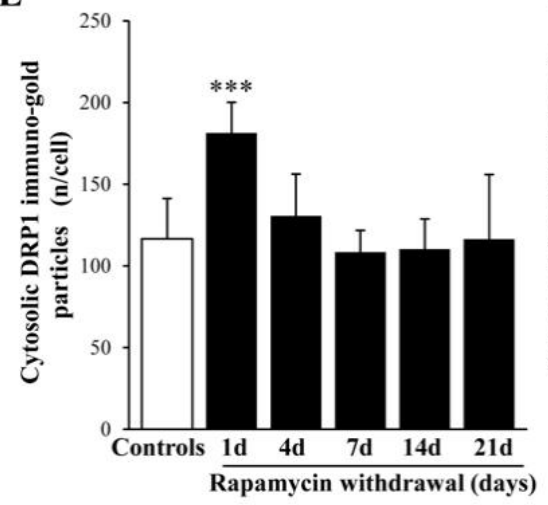

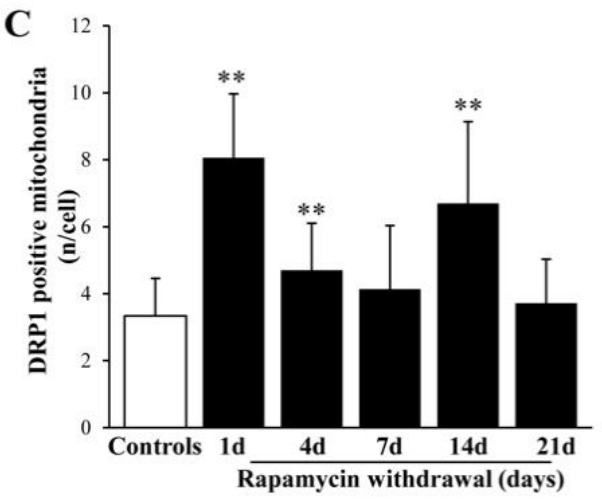

F

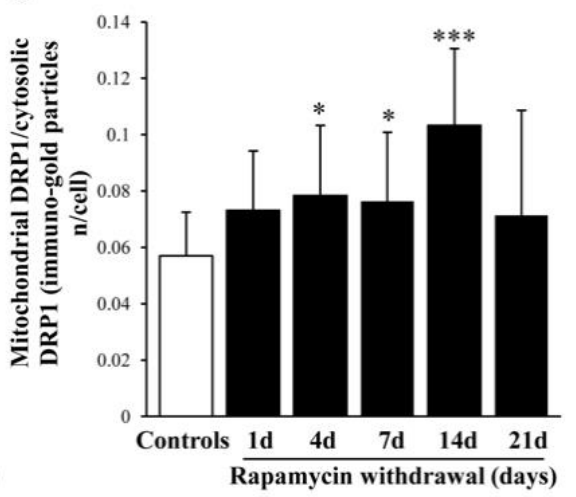

Figure 12. Representative immuno-gold and polarization graphs for the mitochondrial fission marker DRP1. Representative TEM micrograph showing DRP1-positive mitochondria from control (A) and following $1 \mathrm{~d}$ rapamycin withdrawal (B). Arrows point to DIRP1 immuno-gold particles within mitochondria. Graphs report the DRP1-positive mitochondria (C), DRP1 immuno-gold particles within mitochondria (D), the cytosolic amount of DRP1 (E), and the ratio of mitochondrial to cytosolic DRP1 particles (F). Values reported in the graph correspond to the mean $\pm \mathrm{SD}$. Mitochondria were counted in 50 cells per group. ${ }^{*} p \leq 0.05$ compared with controls. ${ }^{* *} p \leq 0.05$ compared with controls and $21 \mathrm{~d}$. ${ }^{* *} p \leq 0.05$ compared with other groups. Scale Bar $=0.5 \mu \mathrm{m}$, Asterisk $\left(^{*}\right)=$ mitochondria.

A

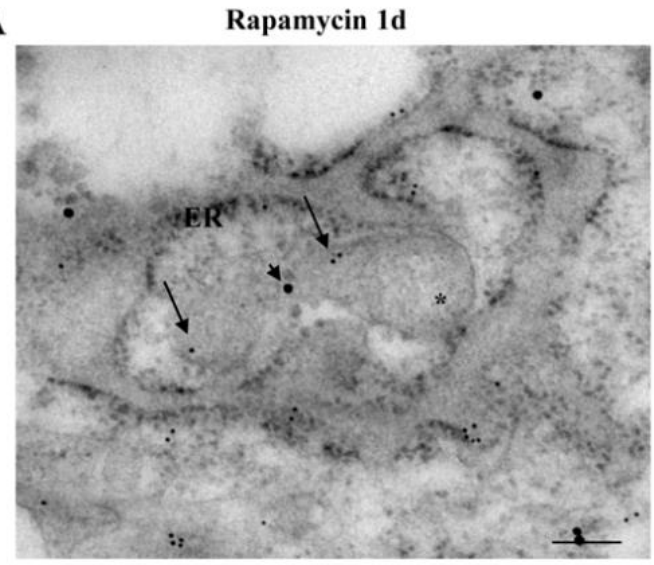

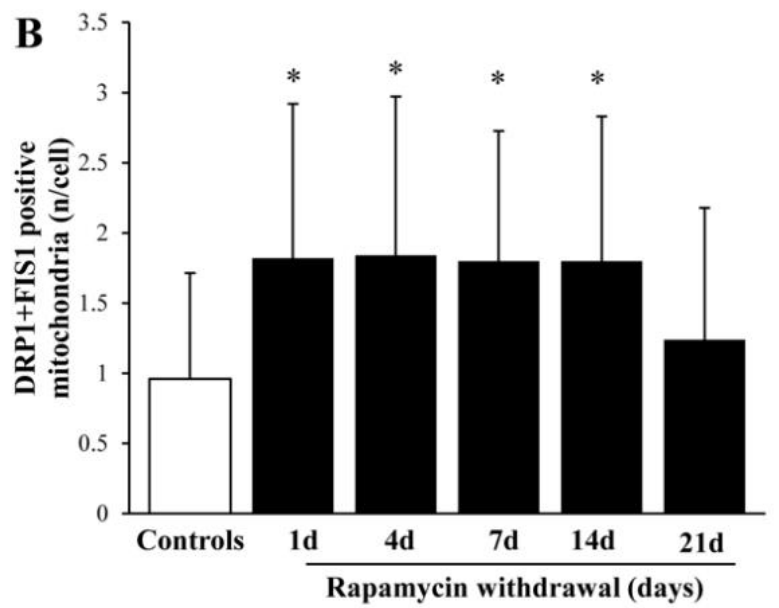

Figure 13. Rapamycin increases the combination of fission markers FIS1 and DRP1. (A) Representative mitochondrion double stained for FIS1 and DRP1 immuno-gold particles (20 nM, arrowhead, and $10 \mathrm{nM}$, arrows respectively) following $1 \mathrm{~d}$ rapamycin withdrawal. Graph (B) reports FIS1+DRP1-positive mitochondria. Values reported in the graph correspond to the mean $\pm \mathrm{SD}$. Mitochondria were counted in 50 cells per group. ${ }^{*} p \leq 0.05$ compared with controls. Scale Bar $=0.25 \mu \mathrm{m}$, Asterisk $\left({ }^{*}\right)=$ mitochondria, $\mathrm{ER}=$ endoplasmic reticulum. 
A

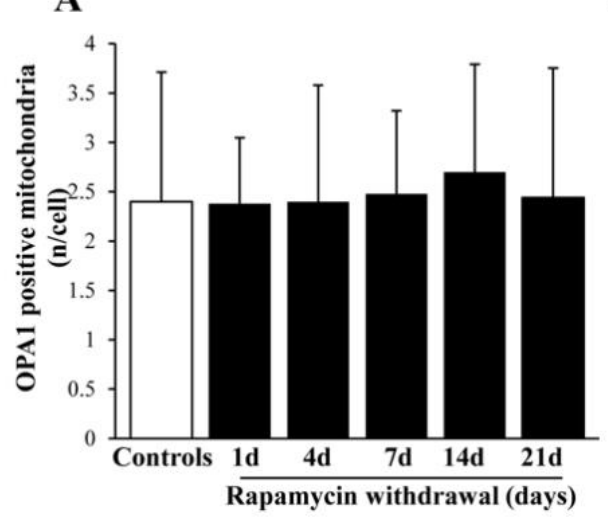

B

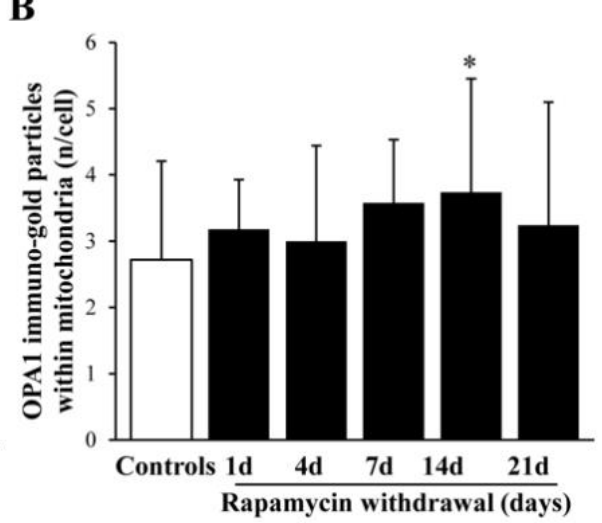

C

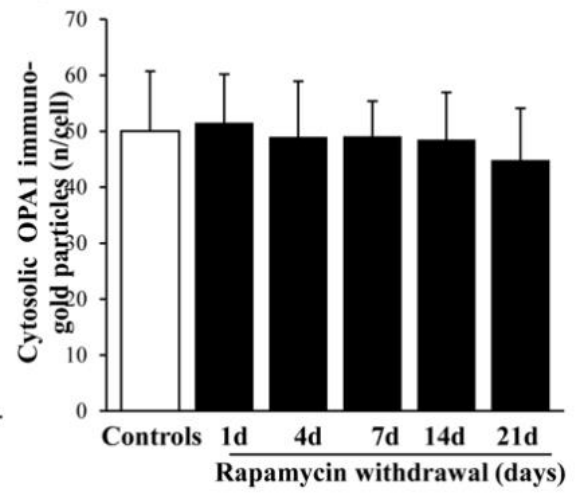

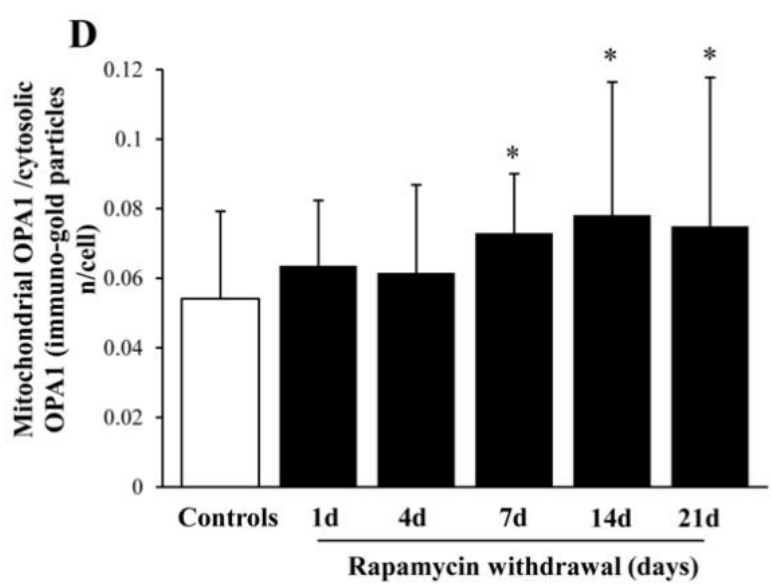

$\mathbf{E}$

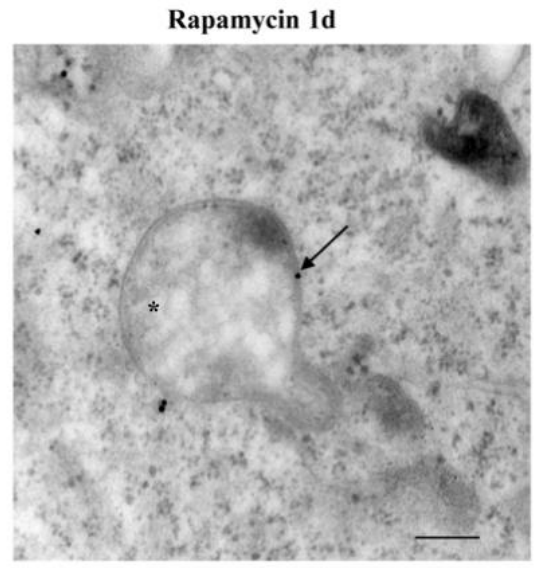

Figure 14. Representative immuno-gold and polarization graphs for the mitochondrial fission marker OPA1. Graphs report the OPA1-positive mitochondria (A), OPA1 immuno-gold particles within mitochondria (B), the cytosolic amount of OPA1 (C), and the ratio of mitochondrial to cytosolic OPA1 particles (D). Representative TEM micrograph showing OPA-positive mitochondria from control (E). Arrows point to OPA1 immuno-gold particles within mitochondria. Values reported in the graph correspond to the mean \pm SD. Mitochondria were counted in 50 cells per group. ${ }^{*} p \leq 0.05$ compared with controls. Scale Bar $=0.3 \mu \mathrm{m}$, Asterisk $\left.{ }^{*}\right)=$ mitochondria.

\section{Discussion}

The present research study quantifies some facets of mitochondrial status in baseline condition and following rapamycin within GBM cells. These cells in baseline conditions feature a marked suppression of autophagy due to mTOR upregulation $[5,10]$.

Despite occurrence of a high number of altered mitochondria are observed in baseline conditions, these cannot be efficiently removed due to an ongoing defect in mitophagy as reported by Fan et al. [45]. Therefore, altered mitochondria accumulate in the cell. Alternatively, other pathways are reported to contribute to the clearance of altered mitochondria. For instance, in patients-derived GBM stem cells, altered mitochondria are transferred to neighboring cells through tunneling nanotubes in the attempt to get reed of dysfunctional organelles [46]. Such a cell-to-cell alternative mitochondrial clearance also occurs between stromal and GBM cells [47].

Evidence is provided here showing that, exposure for $24 \mathrm{~h}$ to $10 \mathrm{nM}$ rapamycin steady increases mitochondrial number at least for $21 \mathrm{~d}$ following rapamycin withdrawal.

Similarly, the amount of altered mitochondria diminishes steadily for $21 \mathrm{~d}$. It is remarkable that both effects persist for a similar amount of time, which suggests that analogous phenomena were causing both increased mitochondrial number and improved mitochondrial morphology. Remarkably, mitochondrial repair and removal quantified at TEM is consistent with mTOR dependent activation of mitochondrial fission and mitophagy genes. 
Genes specifically involved in mitochondrial fission and mitophagy, by acting in combination concretely remove altered mitochondria and increase the amount of healthy organelles. The significance of an increase in those genes promoting fission should be further considered in the light of a reciprocal and mutual influence. In fact, while fissionrelated genes also inhibit fusion [42-44,48]; the fusion gene OPA1 inhibits fission [42,44,48]. Again, fission related genes may also foster another seminal step in mitochondrial dynamics which concerns mitophagy [37-42,44,49-54].

In line with gene expression, we could document an increase of protein detected stoichiometrically, in situ, within mitochondria and scattered in the cytosol. Almost all these proteins were markedly polarized towards mitochondria by rapamycin. This is the case also for LC3, which, despite its vacuolar compartmentalization, is similarly concentrated at mitochondrial level. Analogous findings were obtained when the specific mitophagy proteins ULK1, AMBRA1, PARKIN, and PINK1, which own a significant role in mitophagy. The same happened for fission-related proteins FIS1 and DRP1.

The inhibition of mTOR by acting on these steps of mitochondrial dynamics improves the mitochondrial status in GBM cells contributing to the increase in well-structured mitochondria, which compensate for GBM-specific mitochondrial defect. Thus, when mitophagy is activated, mitochondrial dynamics is synergistically modified [10,55-57] by increasing mitochondrial fission.

In turn, in these experimental conditions a pronounced mitochondrial biogenesis takes place as recently shown under rapamycin administration [10]. This indicates the occurrence of mTOR-dependent cascade, which operates according to an orchestrated pattern, where mitophagy and mitochondrial biogenesis coordinate each other $[57,58]$. Remarkably, the effects described here were long-lasting with at least three weeks of rapamycin withdrawal. This suggests a signaling which brings to mitochondrial plasticity under the control of mTORC1 activity.

When describing cell pathology affecting GBM, an autophagy defect and a mitochondrial dysfunction are generally reported as independent phenomena, while as shown here, both may stem from the same molecular events. It is remarkable that, compartmental polarization, which was previously supposed to solely recruit the autophagy vacuolar compartment, extends even to a higher extent at the level of mitochondria. In the present study, we specifically detected an increase in those mitochondria characterized by small size, remarkable architecture, and strong electron density. This is related to an increased mitophagy and mitochondrial fission, which add on mitochondrial biogenesis previously counted in these experimental conditions. It is remarkable that a number of molecules analyzed in this study as part of specific pathways involved in mitochondrial dynamics are modified persistently and harmonically following rapamycin administration. The persistency of rapamycin-induced gene expression translates into persistent protein and organelle changes, which appears as a strong evidence for plastic phenomena.

The limits of the present study rely on a single cell line being analyzed. Previous findings obtained in primary GBM cell cultures from various patients [5] as well as in multiple cell lines from different sources (A172, U251) [6,10] confirm that, in GBM an mTOR-dependent pathway is overactive. In fact, rapamycin acts in these variable settings according to the very same dose-response curve. Due to the tightened relationship between autophagy and mitophagy, and the mTOR-dependency of both phenomena, it is likely that these findings may have general implications in GBM.

\section{Materials and Methods}

\subsection{Experimental Design}

Experiments were carried out in Uppsala derived human cell line (U87MG) obtained from Cell Bank (IRCCS San Martino-Institute, Genova, Italy). U87MG cells were maintained in DMEM growth medium (Sigma-Aldrich, Saint Louis, MO, USA) containing 10\% Fetal Bovine Serum (FBS, Sigma-Aldrich), 1\% of MEM Non-Essential Amino-Acid (MEM-NEAA, 
Sigma-Aldrich), penicillin, and streptomycin (50 IU / $\mathrm{mL}$ and $100 \mu \mathrm{g}$, respectively, SigmaAldrich) and kept at $37^{\circ} \mathrm{C}$ in a humidified atmosphere containing $5 \% \mathrm{CO}_{2}$.

We applied an experimental design where gene expression and specific ultrastructural morphometry were evaluated following a short administration of rapamycin. Experiments were designed to measure the persistency of genetic and ultrastructural effects produced by rapamycin on mitochondrial morphometry, and genes regulating mitophagy, fission, and fusion. This is measured concomitantly with protein stoichiometry within whole cell and in situ, within mitochondria, where the proteins coded by these genes including their sub-cellular placement were quantified. Therefore, a time course was carried out at $1 \mathrm{~d}, 4 \mathrm{~d}$, $7 \mathrm{~d}, 14 \mathrm{~d}$, and $21 \mathrm{~d}$ following rapamycin withdrawal. This time course is based on previous evidence of long-lasting alterations induced by a short exposure to rapamycin $[5,6]$.

Rapamycin was administered for a short time interval $(24 \mathrm{~h})$. Such a short time was selected in pilot studies by using either MitoTracker-Red and plain TEM to quantify mitochondrial number and mitochondrial alteration, as reported in Figures S1-S5. The doses of rapamycin to be tested were selected in order to include its therapeutic range (3-15 nM) [59]. In fact, rapamycin was administered in pilot experiments at three different doses $(1 \mathrm{nM}, 10 \mathrm{nM}, 100 \mathrm{nM})$. The dose of $10 \mathrm{nM}$ was selected for all the experiments reported in the body of the manuscript for ultrastructural morphometry. Nonetheless, in gene expression experiments we always report two doses of rapamycin, which sometime provides discrepant effects (the $10 \mathrm{nM}$ dose and a higher dose of $100 \mathrm{nM}$ based on the experiments by Supko and Malspeis [60]). These experimental conditions concerning timing and dosing of early rapamycin exposure were kept constant in all further experimental steps designed to assess mitochondrial gene expression and dynamics (mitophagy, fission, and fusion) at various time interval following withdrawal of rapamycin administered.

After rapamycin exposure, the cell culture was washed to remove rapamycin from the cells, which were further re-washed (every three days culture medium was removed and replaced with fresh medium, to keep them alive for long time intervals required by this protocol). Dilutions of rapamycin were prepared from a stock solution of $1 \mathrm{mM}$ rapamycin dissolved in $1.41 \mathrm{M}$ DMSO, which was further solved in culture medium when administered to the cell culture. In this way, the final concentration of DMSO was $0.01 \%$. Control cells were grown in the same culture medium containing $0.01 \%$ DMSO for the same time intervals with the same washing procedure.

\subsection{RNA Extraction}

TRIzol Reagent (Thermo Fisher Scientific, Waltham, MA, USA) was used to isolate total RNA from cell culture. Nanodrop 2000 (Thermo Fisher Scientific) was used to determine the concentration and purity of RNA samples. Total RNA (100 ng) was reversely transcribed (RT) with SuperScript ${ }^{\circledR}$ VILOTM (Thermo Fisher Scientific), according to the manufacturer's instructions.

\section{3. qReal-Time-PCR}

Amplification and detection were performed on a CFX ConnectTM Real Time System (Bio-Rad, Hercules, CA, USA). PCR mix including $10 \mu \mathrm{L}$ SYBR Green PCR Master (Applied Biosystems, Foster City, CA, USA), $0.5 \mu \mathrm{M}$ of each primer and $0.8 \mu \mathrm{L}$ of RT reaction mix, was amplified as follows: $50{ }^{\circ} \mathrm{C}$ for $1 \mathrm{~min}, 95^{\circ} \mathrm{C}$ for $10 \mathrm{~min}$ followed by 40 cycles of $95^{\circ} \mathrm{C}$ for $30 \mathrm{~s}, 54^{\circ} \mathrm{C}$ for $1 \mathrm{~m}$. The primers have been designed using GenBank (http:/ / www.ncbi.nlm.nih.gov/, Table 1, accessed on 7 November 2018).

Positive controls (DNA), negative control (distilled water), and RT-negative controls (total RNA sample) were included in each run.

The relative quantification was calculated using comparative $\mathrm{Ct}$ method (also known as the $\Delta \Delta C T$ method) $[61,62]$, with beta-globin and beta-actin which were selected as internal reference. $\mathrm{Ct}$ values correspond to mean values of each PCR performed in triplicate. Gene expression was confirmed in two independent experiments using both beta-globin and beta-actin as internal reference. Real time PCR was carried out to measure different 
steps of mitochondrial dynamics by selecting the following genes: (i) Mitophagy (VPS34; ULK1; AMBRA1); (ii) fission (FIS1; DRP1); and (iii) fusion (OPA1). In addition, specific genes, which are key to trigger mitophagy (PINK1), or to shuttle mitochondria to the phagophore (PARKIN), were quantified. The latter may be considered as a single functional unit (defined as the PINK1-PARKIN complex), which is activated when mitochondrial clearance is required $[39,41]$.

Table 1. Primers used for quantitative Real Time PCR.

\begin{tabular}{|c|c|c|}
\hline Target Gene & Target Sequence Number & Primer Sequences \\
\hline$D R P 1$ & NM_001330380.1 & $\begin{array}{l}\text { FW 5'-AGCTGCTCAGTATCAGTCTC-3' } \\
\text { RW 5'-GGCAGTCAAAATGTCAATAGT-3' }\end{array}$ \\
\hline FIS1 & NM_016068.3 & $\begin{array}{l}\text { FW 5'-TCAGTCTGAGAAGGCAGCA-3' } \\
\text { RW 5'-CGCTGTTCCTCCTTGCT-3' }\end{array}$ \\
\hline OPA1 & NM_130837.2 & $\begin{array}{l}\text { FW 5'-TTCAGTATCAGCAAAGCT-3' } \\
\text { RW 5'-GAGGGTCCATTTGACTGAC-3' }\end{array}$ \\
\hline ULK1 & NM_003565.3 & $\begin{array}{l}\text { FW 5'-CAGACGACTTCGTCATGGTC-3' } \\
\text { RW 5'-AGCTCCCACTGCACATCAG-3' }\end{array}$ \\
\hline VPS34 & NM_002647.4 & $\begin{array}{l}\text { FW 5'-GGGGAAGCAGAGAAGTTTCA- }{ }^{\prime} \\
\text { RW 5'-TCTTCCCTTCCAAGCTTCCT- } 3^{\prime}\end{array}$ \\
\hline$A M B R A 1$ & NM_001367468.1 & $\begin{array}{l}\text { FW 5' 5'-GAGCACCCAATTTACCCAGA-3' } \\
\text { RW 5'-GATCATCCTCTGGGCGTAGTA-3' }\end{array}$ \\
\hline PARKIN & NM_004562.3 & $\begin{array}{l}\text { FW 5'-TGAGAAGCTGGATTACCATC-3' } \\
\text { RW 5'-TTGAGAGTGACACAGATGACCT-3 }\end{array}$ \\
\hline PINK1 & NM_032409.3 & $\begin{array}{l}\text { FW 5'-GGCTTTCGGCTGGAGGAGTA-3' } \\
\text { RW 5'-GCTCGCTGGGACCAGCTCC-3'3 }\end{array}$ \\
\hline$\beta$-Actin & NM_001101.3 & $\begin{array}{l}\text { FW 5'-GTGCGTGACATTAAGGAG-3' } \\
\text { RW 5'-GCCAGACAGCACTGTGT-3' }\end{array}$ \\
\hline$\beta$-Globin & NM_000518.4 & $\begin{array}{l}\text { FW 5'-CTAAGGTGAAGGCTCATG-3' } \\
\text { RW 5 5'-GATAGGCAGCCTGCACT-3 }\end{array}$ \\
\hline
\end{tabular}

Thus, after a short challenge with rapamycin, the experimental design proceeded at $1 \mathrm{~d}, 4 \mathrm{~d}, 7 \mathrm{~d}, 14 \mathrm{~d}$, and $21 \mathrm{~d}$ of rapamycin withdrawal.

\subsection{MitoTracker-Red}

In order to check whether the number of healthy mitochondria in living cells undergo an increase under the effects of rapamycin compared with GBM cells in baseline conditions, we carried out fluorescence for MitoTracker-Red dye [34]. Briefly, $5 \times 10^{2} \mathrm{GBM}$ cells were grown in 24 well plates containing $1 \mathrm{~mL} /$ well of culture medium. At the end of each experiment, the medium was removed and cells were incubated with a solution of MTR $250 \mathrm{nM}$ in a serum free culture medium for $45 \mathrm{~min}$, at $37^{\circ} \mathrm{C}$, and $5 \% \mathrm{CO}_{2}$. At the end of incubation, MTR solution was removed and fresh pre-warmed medium was added. Stained cells were analyzed at fluorescence microscopy (Leica Microsystems); optical density was calculated using ImageJ software.

\subsection{Transmission Electron Microscopy (TEM)}

For TEM, U87MG cells $\left(10^{6}\right)$ were seeded into $10 \mathrm{~mm}$ diameter dishes with $5 \mathrm{~mL}$ of culture medium. After removing culture medium, a fixing solution $(2.0 \%$ paraformaldehyde $/ 0.1 \%$ glutaraldehyde, both dissolved in $0.1 \mathrm{M}$ PBS pH 7.4) was added to the cell culture for $90 \mathrm{~min}$ at $4{ }^{\circ} \mathrm{C}$. Cells were gently scraped from the plate, collected into vials, and centrifuged at 10,000 rpm for $10 \mathrm{~min}$ to deposit a cell pellet. After removing supernatant, this pellet was re-suspended in PBS and centrifuged again at $8000 \mathrm{rpm}$. After removing supernatant, the second pellet which was free of aldehydes remnants, was post-fixed in $1 \%$ osmium tetroxide $\left(\mathrm{OsO}_{4}\right)$ for $1 \mathrm{~h}$ at $4{ }^{\circ} \mathrm{C}$. After washing in PBS the post-fixed pellet was dehydrated in a gradient of ethanol solutions $50 \%, 70 \%, 90 \%$, and $95 \%$, each for $5 \mathrm{~min}$, to reach $100 \%$ ethanol for $60 \mathrm{~min}$. This was followed by adding a solution of propylene oxide for $15 \mathrm{~min}$ to produce an interface between the samples and the epoxy resin, which is 
more compatible compared with alcohol. In fact, when propylene oxide was removed the pellet was progressively embedded, at first in a 50\% solution of epon-araldite in propylene oxide, overnight. Finally, the pellet was embedded in pure epon-araldite for $72 \mathrm{~h}$, at $60{ }^{\circ} \mathrm{C}$ to improve resin polymerization. Following removal from the oven, after a short interval to cool the embedded sample, this was a firm material, ready for cutting. Thus, ultrathin sections could be firmly and homogeneously cut at ultra-microtome (Leica Microsystems) and either plain TEM or post-embedding immuno-electron microscopy were carried out. Ultrathin sections were observed at Jeol JEM SX100 electron-microscopy (Jeol, Tokyo, Japan) at an acceleration voltage of $80 \mathrm{kV}$.

\subsubsection{Post-Embedding Immuno-Electron Microscopy}

Post-embedding immuno-electron microscopy is a procedure, which requires optimal fixing of the tissue and its embedding. In previous studies [39,63-65] we validated the use of $\mathrm{OsO}_{4}$ and epoxy resin to preserve ultrastructural morphometry [39,63-66]. In fact, a combination of aldehydes, $\mathrm{OsO}_{4}$, and epoxy resin allows a minimal epitope covering, while preserving sub-cellular architecture. In particular, $\mathrm{OsO}_{4}$ binds to lipid membranes, making them well marked compared with surrounding material. This allows specific detection of each organelle contour and, acting as a contrast enhancer magnifies the subcellular trim. Moreover, epoxy resin better preserves cell architecture compared with acrylic resin.

Post-embedding immuno-electron microscopy was carried out to test different antibodies in ultrathin sections. We used gold-conjugated secondary antibodies, which allow stoichiometric detection and localization of the antigens within sub-cellular structures [67]. Ultrathin sections were collected on nickel grids and processed for protein detection, as detailed in Table 2 . The oxidizing agent sodium metaperiodate $\left(\mathrm{NaIO}_{4}\right)$ was used to partially remove $\mathrm{OsO}_{4}$ as much as needed to unmask antigens [68]. The sodium metaperiodate attacks the hydrophobic alkane side-chains of epoxy resin thus making sections more hydrophilic, which allows an intimate contact between immuno-gold-conjugated antibodies and section surface antigens [63-65]. Nickel grids were incubated with aqueous saturated $\mathrm{NaIO}_{4}$ solution for $30 \mathrm{~min}$, at $21^{\circ} \mathrm{C}$.

Table 2. Sources and identification of each antibody used in the study.

\begin{tabular}{cccc}
\hline Antibodies & Distributors & Cod. N & RRID \\
\hline Rabbit anti-LC3 & Abcam & ab128025 & AB_11143008 \\
Rabbit anti-FIS1 & GeneTex & GTX111010 & AB_10731288 \\
Mouse anti-DRP1 & Abcam & ab56788 & AB_941306 \\
Rabbit anti-OPA1 & Abcam & ab90857 & AB_2050139 \\
Mouse anti-PINK1 & Abcam & ab186303 & AB_2827698 \\
Rabbit anti-PARKIN & Millipore & AB5112 & AB_2283497 \\
Rabbit anti-ULK1 & Cell Signaling Technology & D8H5 & AB_11178668 \\
Rabbit anti-AMBRA1 & Abcam & ab 59141 & AB_941614 \\
Rabbit anti-Vps34 & Thermo Fisher Scientific & PA1-46456 & AB_2283904 \\
EM Goat anti-Rabbit IgG, gold conjugated antibody & BBInternational & EM.GAR 20 & AB_1769136 \\
EM Goat anti-Rabbit IgG, gold conjugate antibody & BBInternational & EM.GAR 10 & AB_1769128 \\
\hline
\end{tabular}

Here, we report the rough list of primary antibodies used: (i) LC3, (Abcam, Cambridge, UK), (ii) VPS34 (Thermo Fisher Scientific), (iii) ULK1 (Cell Signaling Thechnology, Danvers, MA, USA), (iv) AMBRA1 (Abcam), (v) PARKIN (Millipore, Burlington, MA, USA), (vi) PINK1 (Abcam), (vii) FIS1 (GeneTex, Irvine, CA, USA), (viii) DRP1 (Abcam). (ix) OPA1 (Abcam).

After washing in PBS, grids were incubated on drops of blocking buffer $(10 \%$ goat serum and $0.2 \%$ saponin in PBS) for $20 \mathrm{~min}$, at $21^{\circ} \mathrm{C}$, and then, with a single primary antibody (diluted 1:20, in PBS containing 1\% goat serum and $0.2 \%$ saponin) or with two antibodies in order to detect co-localization (FIS1+DRP1 both diluted 1:20) in a humidified chamber overnight at $4{ }^{\circ} \mathrm{C}$. 
After washing in cold PBS, ultrathin sections were incubated on drops of blocking buffer containing gold-conjugated secondary antibodies $(10 \mathrm{~nm}$ gold particles; $20 \mathrm{~nm}$ gold particles, BB International, Treviso, Italy), diluted (1:20) for $1 \mathrm{~h}$ at $21^{\circ} \mathrm{C}$. Then, grids were incubated with $1 \%$ glutaraldehyde for $3 \mathrm{~min}$, and they were washed in distilled water to remove salt traces and prevent uranyl-acetate precipitation. Grids were counterstained with a saturated solution in distilled water of uranyl acetate and lead citrate to be ready for electron microscopy. To control for method some sections were incubated with secondary antibody only.

\subsubsection{Ultra-Structural Analysis of Mitochondria}

Grids containing non-serial ultrathin sections (90 nm thick) were examined at $6000 \times$ magnification to count both total number and altered number of mitochondria per cell. The number of immuno-gold particles was counted at $8000 \times$. Several grids were observed in order to count a number of at least 50 cells per each experimental group. Starting from a grid square corner, the whole sectioned pellet embedded within that grid square was scanned in equally spaced parallel sweeps across the specimens. The counts were repeated at least twice by two blind observers. Mitochondria were easily identified at TEM for their shape and structure consisting in a typical double-membrane limiting an inter-membrane ("inter-mitochondrial") space and an area internal to the inner membrane, where a homogeneous matrix is interrupted quite regularly by intermingled crests (cristae), in a sort of labyrinth system. Although the general morphology of the mitochondria is standardized at ultrastructural level, many variations may be noticed at high magnification within the context of specific cell metabolism and cytopathology $[10,69]$. All these variants can be appreciated concomitantly, when working in GBM cells. Nonetheless, under the effects of rapamycin there is an evident shift towards a specific morphology, which will be reported in the results section. In fact, when control cells possess a defect in mitochondrial removal and fission and organelles tend to merge and enlarge, the effects of rapamycin promote the opposite phenotype, as we shall see.

\subsection{Statistics}

For MitoTracker-Red, stained cells were analyzed at fluorescence microscopy (Leica Microsystems); optical density was calculated using ImageJ software. Values are expressed as the percentage of the fluorescent densitometry of each sample with respect to the controls $(\mathrm{N}=50)$. Inferential statistics to compare groups was carried out by using One-way analysis of variance, ANOVA, with Scheffè's post-hoc analysis $\left(\mathrm{H}_{0}\right.$, null hypothesis, was rejected for $p \leq 0.05)$.

For qReal Time-PCR experiments, statistical analyses using one-way analysis of variance (ANOVA) followed by Bonferroni test, using GraphPad Prism version 6.0 has been used to test differences in gene expression in baseline conditions and under the effects of rapamycin $(p \leq 0.05)$.

For ultrastructural morphometry, the number of total and altered mitochondria per cell were quantified along as the number of immuno-gold particles both in the cytosol and within mitochondria and the cytosolic/mitochondrial ratio for the following antigens: LC3, VPS34, ULK1; AMBRA1, PARKIN, PINK1, FIS1, DRP1, OPA1. Data are the mean or the mean percentage $\pm S D$ per cell ( $\mathrm{N}=50$ cells per group). Inferential statistics to compare groups was carried out by using One-way analysis of variance, ANOVA, with Scheffè's post-hoc analysis $\left(\mathrm{H}_{0}\right.$, null hypothesis, was rejected for $\left.p \leq 0.05\right)$.

Supplementary Materials: The following are available online at https:/ / www.mdpi.com/article/10 .3390/ijms22105379/s1.

Author Contributions: Study design and original draft preparation, R.F., P.L. and F.F. (Francesco Fornai); Electron microscopy, P.L., A.F. (Alessandra Falleni) and F.F. (Federica Fulceri); RT-PCR experiments R.F. and S.G.; Cell cultures F.B.; data curation, R.F., P.L., F.F. (Federica Fulceri), F.B., C.L.B., A.F. (Alessandra Falleni), S.G. and F.F.; review and editing, R.F., P.L., F.F. (Federica Fulceri), F.B. 
and A.F. (Alessandra Falleni); conceptualization, A.F. (Alessandro Frati); conceptualization, writing, and supervision, F.F. (Francesco Fornai). All authors have read and agreed to the published version of the manuscript.

Funding: The present research was funded by Ministero della Salute (Ricerca Corrente 2021).

Conflicts of Interest: The authors declare no conflict of interest.

\section{References}

1. Jiang, H.; White, E.J.; Conrad, C.; Gomez-Manzano, C.; Fueyo, J. Autophagy pathways in glioblastoma. Methods Enzymol. 2009, 453, 273-286.

2. Zhao, Y.; Huang, Q.; Yang, J.; Lou, M.; Wang, A.; Dong, J.; Qin, Z.; Zhang, T. Autophagy impairment inhibits differentiation of glioma stem/progenitor cells. Brain Res. 2010, 1313, 250-258. [CrossRef]

3. Klionsky, D.J.; Abdel-Aziz, A.K.; Abdelfatah, S.; Abdellatif, M.; Abdoli, A.; Abel, S.; Abeliovich, H.; Abildgaard, M.H.; Abudu, Y.P.; Acevedo-Arozena, A.; et al. Guidelines for the use and interpretation of assays for monitoring autophagy (4th edition). Autophagy 2021, 17, 1-382. [PubMed]

4. Zhuang, W.; Li, B.; Long, L.; Chen, L.; Huang, Q.; Liang, Z. Induction of autophagy promotes differentiation of glioma-initiating cells and their radiosensitivity. Int. J. Cancer 2011, 129, 2720-2731. [CrossRef] [PubMed]

5. Arcella, A.; Biagioni, F.; Oliva, M.A.; Bucci, D.; Frati, A.; Esposito, V.; Cantore, G.; Giangaspero, F.; Fornai, F. Rapamycin inhibits the growth of glioblastoma. Brain Res. 2013, 1495, 37-51. [CrossRef]

6. Ferrucci, M.; Biagioni, F.; Lenzi, P.; Gambardella, S.; Ferese, R.; Calierno, M.T.; Falleni, A.; Grimaldi, A.; Frati, A.; Esposito, V.; et al. Rapamycin promotes differentiation increasing $\beta$ III-tubulin, NeuN, and NeuroD while suppressing nestin expression in glioblastoma cells. Oncotarget 2017, 8, 29574-29599. [CrossRef] [PubMed]

7. Ryskalin, L.; Gaglione, A.; Limanaqi, F.; Biagioni, F.; Familiari, P.; Frati, A.; Esposito, V.; Fornai, F. The Autophagy Status of Cancer Stem Cells in Gliobastoma Multiforme: From Cancer Promotion to Therapeutic Strategies. Int. J. Mol. Sci. 2019, $20,3824$. [CrossRef] [PubMed]

8. Ryskalin, L.; Lazzeri, G.; Flaibani, M.; Biagioni, F.; Gambardella, S.; Frati, A.; Fornai, F. mTOR-Dependent Cell Proliferation in the Brain. Biomed. Res. Int. 2017, 2017, 7082696. [CrossRef] [PubMed]

9. Ryskalin, L.; Limanaqi, F.; Biagioni, F.; Frati, A.; Esposito, V.; Calierno, M.T.; Lenzi, P.; Fornai, F. The emerging role of m-TOR up-regulation in brain Astrocytoma. Histol. Histopathol. 2017, 32, 413-431. [PubMed]

10. Ferese, R.; Lenzi, P.; Fulceri, F.; Biagioni, F.; Fabrizi, C.; Gambardella, S.; Familiari, P.; Frati, A.; Limanaqi, F.; Fornai, F. Quantitative Ultrastructural Morphometry and Gene Expression of mTOR-Related Mitochondriogenesis within Glioblastoma Cells. Int. J. Mol. Sci. 2020, 21, 4570. [CrossRef]

11. Ryskalin, L.; Biagioni, F.; Lenzi, P.; Frati, A.; Fornai, F. mTOR Modulates Intercellular Signals for Enlargement and Infiltration in Glioblastoma Multiforme. Cancers 2020, 12, 2486. [CrossRef] [PubMed]

12. Arcella, A.; Limanaqi, F.; Ferese, R.; Biagioni, F.; Oliva, M.A.; Storto, M.; Fanelli, M.; Gambardella, S.; Fornai, F. Dissecting Molecular Features of Gliomas: Genetic Loci and Validated Biomarkers. Int. J. Mol. Sci. 2020, 21, 685. [CrossRef]

13. Arismendi-Morillo, G. Electron microscopy morphology of the mitochondrial network in gliomas and their vascular microenvironment. Biochim. Biophys. Acta 2011, 1807, 602-608. [CrossRef]

14. Arismendi-Morillo, G.; Castellano-Ramírez, A.; Seyfried, T.N. Ultrastructural characterization of the Mitochondria-associated membranes abnormalities in human astrocytomas: Functional and therapeutics implications. Ultrastruct. Pathol. 2017, 41, 234-244. [CrossRef]

15. Deighton, R.F.; Le Bihan, T.; Martin, S.F.; Gerth, A.M.J.; McCulloch, M.; Edgar, J.M.; Kerr, L.E.; Whittle, I.R.; McCulloch, J. Interactions among mitochondrial proteins altered in glioblastoma. J. Neurooncol. 2014, 118, 247-256. [CrossRef] [PubMed]

16. Liang, B.C.; Grootveld, M. The importance of mitochondria in the tumourigenic phenotype: Gliomasas the paradigm. Int. J. Mol. Med. 2011, 27, 159-171. [CrossRef] [PubMed]

17. Epple, L.M.; Dodd, R.D.; Merz, A.L.; Dechkovskaia, A.M.; Herring, M.; Winston, B.A.; Lencioni, A.M.; Russell, R.L.; Madsen, H.; Nega, M.; et al. Induction of the Unfolded Protein Response Drives Enhanced Metabolism and Chemoresistance in Glioma Cells. PLOS ONE. 2013, 8, e73267. [CrossRef] [PubMed]

18. Redzic, J.S.; Gomez, J.D.; Hellwinkel, J.E.; Anchordoquy, T.J.; Graner, M.W. Proteomic analyses of brain tumor cell lines amidst the unfolded protein response. Oncotarget 2016, 7, 47831-47847. [CrossRef] [PubMed]

19. Corsaro, A.; Bajetto, A.; Thellung, S.; Begani, G.; Villa, V.; Nizzari, M.; Pattarozzi, A.; Solari, A.; Gatti, M.; Pagano, A.; et al. Cellular prion protein controls stem cell-like properties of human glioblastoma tumor-initiating cells. Oncotarget 2016, 7, 38638-38657. [CrossRef]

20. Ihenacho, U.K.; Meacham, K.A.; Harwig, M.C.; Widlansky, M.E.; Hill, R.B. Mitochondrial Fission Protein 1: Emerging Roles in Organellar Form and Function in Health and Disease. Front. Endocrinol. 2021, 12, 660095. [CrossRef]

21. Westermann, B. Mitochondrial fusion and fission in cell life and death. Nat. Rev. Mol. Cell. Biol. 2010, 11, 872-884. [CrossRef]

22. Gustafsson, A.B.; Dorn, G.W., 2nd. Evolving and Expanding the Roles of Mitophagy as a Homeostatic and Pathogenic Process. Physiol. Rev. 2019, 99, 853-892. [CrossRef]

23. Vara-Perez, M.; Felipe-Abrio, B.; Agostinis, P. Mitophagy in Cancer: A Tale of Adaptation. Cells 2019, 8, 493. [CrossRef] [PubMed] 
24. Chakravarti, A.; Zhai, G.; Suzuki, Y.; Sarkesh, S.; Black, P.M.; Muzikansky, A.; Loeffler, J.S. The prognostic significance of phosphatidylinositol 3-kinase pathway activation in human gliomas. J. Clin. Oncol. 2004, 22, 1926-1933. [CrossRef] [PubMed]

25. Sunayama, J.; Sato, A.; Matsuda, K.; Tachibana, K.; Suzuki, K.; Narita, Y.; Shibui, S.; Sakurada, K.; Kayama, T.; Tomiyama, A.; et al. Dual blocking of mTor and PI3K elicits a prodifferentiation effect on glioblastoma stem-like cells. Neuro. Oncol. 2010, 12, 1205-1219. [CrossRef] [PubMed]

26. Li, X.Y.; Zhang, L.Q.; Zhang, X.G.; Li, X.; Ren, Y.B.; Ma, X.Y.; Li, X.G.; Wang, L.X. Association between AKT/mTOR signalling pathway and malignancy grade of human gliomas. J. Neuroncol. 2011, 103, 453-458. [CrossRef] [PubMed]

27. Fan, Q.W.; Weiss, W.A. Autophagy and Akt promote survival in glioma. Autophagy 2011, 7, 536-538. [CrossRef] [PubMed]

28. Galan-Moya, E.M.; Le Guelte, A.; Lima Fernandes, E.; Thirant, C.; Dwyer, J.; Bidere, N.; Couraud, P.O.; Scott, M.G.; Junier, M.P.; Chneiweiss, H.; et al. Secreted factors from brain endothelial cells maintain glioblastoma stem-like cell expansion through the mTOR pathway. EMBO Rep. 2011, 12, 470-476. [CrossRef] [PubMed]

29. Jhanwar-Uniyal, M.; Jeevan, D.; Neil, J.; Shannon, C.; Albert, L.; Murali, R. Deconstructing mTOR complexes in regulation of glioblastoma multiforme and its stem cells. Adv. Biol. Regul. 2013, 53, 202-210. [CrossRef] [PubMed]

30. Catalano, M.; D'Alessandro, G.; Lepore, F.; Corazzari, M.; Caldarola, S.; Valacca, C.; Faienza, F.; Esposito, V.; Limatola, C.; Cecconi, F.; et al. Autophagy induction impairs migration and invasion by reversing EMT in glioblastoma cells. Mol. Oncol. 2015, 9, 1612-1625. [CrossRef] [PubMed]

31. Chandrika, G.; Natesh, K.; Ranade, D.; Chugh, A.; Shastry, P. Suppression of the invasive potential of glioblastoma cells by mTOR inhibitors involves modulation of NFKB and PKC- $\alpha$ signaling. Sci. Rep. 2016, 6, 22455. [CrossRef] [PubMed]

32. Garros-Regulez, L.; Aldaz, P.; Arrizabalaga, O.; Moncho-Amor, V.; Carrasco-Garcia, E.; Manterola, L.; Moreno-Cugnon, L.; Barrena, C.; Villanua, J.; Ruiz, I.; et al. mTOR inhibition decreases SOX2-SOX9 mediated glioma stem cell activity and temozolomide resistance. Expert Opin. Ther. Targets 2016, 20, 393-405. [CrossRef] [PubMed]

33. Ma, Y.; Wang, L.; Jia, R. The role of mitochondrial dynamics in human cancers. Am. J. Cancer Res. 2020, 10, 1278-1293. [PubMed]

34. Gautam, N.; Sankaran, S.; Yason, J.A.; Tan, K.S.W.; Gascoigne, N.R.J. A high content imaging flow cytometry approach to study mitochondria in T cells: MitoTracker Green FM dye concentration optimization. Methods 2018, 134-135, 11-19. [CrossRef] [PubMed]

35. Nazio, F.; Carinci, M.; Valacca, C.; Bielli, P.; Strappazzon, F.; Antonioli, M.; Ciccosanti, F.; Rodolfo, C.; Campello, S.; Fimia, G.M.; et al. Fine-tuning of ULK1 mRNA and protein levels is required for autophagy oscillation. J. Cell. Biol. 2016, 215, 841-856. [CrossRef] [PubMed]

36. Nazio, F.; Strappazzon, F.; Antonioli, M.; Bielli, P.; Cianfanelli, V.; Bordi, M.; Gretzmeier, C.; Dengjel, J.; Piacentini, M.; Fimia, G.M.; et al. mTOR inhibits autophagy by controlling ULK1 ubiquitylation, self-association and function through AMBRA1 and TRAF6. Nat. Cell. Biol. 2013, 15, 406-416. [CrossRef]

37. Strappazzon, F.; Nazio, F.; Corrado, M.; Cianfanelli, V.; Romagnoli, A.; Fimia, G.M.; Campello, S.; Nardacci, R.; Piacentini, M.; Campanella, M.; et al. AMBRA1 is able to induce mitophagy via LC3 binding, regardless of PARKIN and p62/SQSTM1. Cell Death Differ. 2015, 22, 419-432. [CrossRef]

38. Van Humbeeck, C.; Cornelissen, T.; Hofkens, H.; Mandemakers, W.; Gevaert, K.; De Strooper, B.; Vandenberghe, W. Parkin interacts with Ambra1 to induce mitophagy. J. Neurosci. 2011, 31, 10249-10261. [CrossRef] [PubMed]

39. Lenzi, P.; Marongiu, R.; Falleni, A.; Gelmetti, V.; Busceti, C.L.; Michiorri, S.; Valente, E.M.; Fornai, F. A subcellular analysis of genetic modulation of PINK1 on mitochondrial alterations, autophagy and cell death. Arch. Ital. Biol. 2012, 150, 194-217. [PubMed]

40. Scarffe, L.A.; Stevens, D.A.; Dawson, V.L.; Dawson, T.M. Parkin and PINK1: Much more than mitophagy. Trends Neurosci. 2014, 37, 315-324. [CrossRef]

41. Yoo, S.M.; Jung, Y.K. A Molecular Approach to Mitophagy and Mitochondrial Dynamics. Mol. Cells 2018, 41, 18-26.

42. Archer, S.L. Mitochondrial dynamics-Mitochondrial fission and fusion in Human diseases. N. Engl. J. Med. 2013, 369, $2236-2251$. [CrossRef] [PubMed]

43. Yu, R.; Jin, S.-B.; Lendahl, U.; Nistér, M.; Zhao, J. Human Fis1 regulates mitochondrial dynamics through inhibition of the fusion machinery. EMBO J. 2019, 38, e99748. [CrossRef] [PubMed]

44. Twig, G.; Elorza, A.; Molina, A.J.A.; Mohamed, H.; Wikstrom, J.D.; Walzer, G.; Stiles, L.; Haigh, S.E.; Katz, S.; Las, G.; et al. Fission and selective fusion govern mitochondrial segregation and elimination by autophagy. EMBO J. 2008, 27, 433-446. [CrossRef] [PubMed]

45. Fan, W.; Song, Y.; Ren, Z.; Cheng, X.; Li, P.; Song, H.; Jia, L. Glioma cells are resistant to inflammation-induced alterations of mitochondrial dynamics. Int. J. Oncol. 2020, 57, 1293-1306. [CrossRef] [PubMed]

46. Pinto, G.; Saenz-de-Santa-Maria, I.; Chastagner, P.; Perthame, E.; Delmas, C.; Toulas, C.; Moyal-Jonathan-Cohen, E.; Brou, C.; Zurzolo, C. Patient-derived glioblastoma stem cells transfer mitochondria through tunneling nanotubes in tumor organoids. Biochem. J. 2021, 478, 21-39. [CrossRef] [PubMed]

47. Salaud, C.; Alvarez-Arenas, A.; Geraldo, F.; Belmonte-Beitia, J.; Calvo, G.F.; Gratas, C.; Pecqueur, C.; Garnier, D.; Pérez-Garcià, V.; Vallette, F.M.; et al. Mitochondria transfer from tumor-activated stromal cells (TASC) to primary Glioblastoma cells. Biochem. Biophys. Res. Commun. 2020, 533, 139-147. [CrossRef] [PubMed]

48. Spurlock, B.; Tullet, J.M.A.; Hartman, J.L.; Mitra, K. Interplay of mitochondrial fission-fusion with cell cycle regulation: Possible impacts on stem cell and organismal aging. Exp. Gerontol. 2020, 135, 110919. [CrossRef] 
49. Cianfanelli, V.; Nazio, F.; Cecconi, F. Connecting autophagy: AMBRA1 and its network of regulation. Mol. Cell Oncol. 2015, 2, e970059. [CrossRef]

50. Clark, I.E.; Dodson, M.W.; Jiang, C.; Cao, J.H.; Huh, J.R.; Seol, J.H.; Yoo, S.J.; Hay, B.A.; Guo, M. Drosophila pink1 is required for mitochondrial function and interacts genetically with parkin. Nature 2006, 441, 1162-1166. [CrossRef]

51. Park, J.; Lee, S.B.; Lee, S.; Kim, Y.; Song, S.; Kim, S.; Bae, E.; Kim, J.; Shong, M.; Kim, J.M.; et al. Mitochondrial dysfunction in Drosophila PINK1 mutants is complemented by parkin. Nature 2006, 441, 1157-1161. [CrossRef] [PubMed]

52. Poole, A.C.; Thomas, R.E.; Andrews, L.A.; McBride, H.M.; Whitworth, A.J.; Pallanck, L.J. The PINK1/Parkin pathway regulates mitochondrial morphology. Proc. Natl. Acad. Sci. USA 2008, 105, 1638-1643. [CrossRef]

53. Wu, W.; Tian, W.; Hu, Z.; Chen, G.; Huang, L.; Li, W.; Zhang, X.; Xue, P.; Zhou, C.; Liu, L.; et al. ULK1 translocates to mitochondria and phosphorylates FUNDC1 to regulate mitophagy. EMBO Rep. 2014, 15, 566-575. [CrossRef] [PubMed]

54. Murakawa, T.; Okamoto, K.; Omiya, S.; Taneike, M.; Yamaguchi, O.; Otsu, K. A Mammalian Mitophagy Receptor, Bcl2-L-13, Recruits the ULK1 Complex to Induce Mitophagy. Cell Rep. 2019, 26, 338-345. [CrossRef]

55. Palikaras, K.; Lionaki, E.; Tavernarakis, N. Mechanisms of mitophagy in cellular homeostasis, physiology and pathology. Nat. Cell. Biol. 2018, 20, 1013-1022. [CrossRef] [PubMed]

56. Lou, G.; Palikaras, K.; Lautrup, S.; Scheibye-Knudsen, M.; Tavernarakis, N.; Fang, E.F. Mitophagy and Neuroprotection. Trends Mol. Med. 2020, 26, 8-20. [CrossRef] [PubMed]

57. Palikaras, K.; Tavernarakis, N. Mitochondrial homeostasis: The interplay between mitophagy and mitochondrial biogenesis. Exp. Gerontol. 2014, 56, 182-188. [CrossRef]

58. Palikaras, K.; Lionaki, E.; Tavernarakis, N. Balancing mitochondrial biogenesis and mitophagy to maintain energy metabolism homeostasis. Cell Death Differ. 2015, 22, 1399-1401. [CrossRef]

59. Kirchner, G.I.; Meier-Wiedenbach, I.; Manns, M.P. Clinical pharmacokinetics of everolimus. Clin. Pharmacokinet. 2004, 43, 83-95. [CrossRef]

60. Supko, J.G.; Malspeis, L. Dose-dependent pharmacokinetics of rapamycin-28-N,N-dimethylglycinate in the mouse. Cancer Chemother. Pharmacol. 1994, 33, 325-330. [CrossRef]

61. Schefe, J.H.; Lehmann, K.E.; Buschmann, I.R.; Unger, T.; Funke-Kaiser, H. Quantitative real-time RT-PCR data analysis: Current concepts and the novel "gene expression's CT difference" formula. J. Mol. Med. 2006, 84, 901-910. [CrossRef] [PubMed]

62. Yuan, J.S.; Reed, A.; Chen, F.; Stewart, C.N., Jr. Statistical analysis of real-time PCR data. BMC Bioinformatics 2006, 7, 85. [CrossRef] [PubMed]

63. Natale, G.; Lenzi, P.; Lazzeri, G.; Falleni, A.; Biagioni, F.; Ryskalin, L.; Fornai, F. Compartment-dependent mitochondrial alterations in experimental ALS, the effects of mitophagy and mitochondriogenesis. Front. Cell. Neurosci. 2015, 9, 434. [CrossRef] [PubMed]

64. Lenzi, P.; Lazzeri, G.; Biagioni, F.; Busceti, C.L.; Gambardella, S.; Salvetti, A.; Fornai, F. The Autophagoproteasome a Novel Cell Clearing Organelle in Baseline and Stimulated Conditions. Front. Neuroanat. 2016, 10, 78. [CrossRef]

65. Lazzeri, G.; Biagioni, F.; Fulceri, F.; Busceti, C.L.; Scavuzzo, M.C.; Ippolito, C.; Salvetti, A.; Lenzi, P.; Fornai, F. mTOR Modulates Methamphetamine-Induced Toxicity through Cell Clearing Systems. Oxid. Med. Cell Longev. 2018, 2018, 6124745. [CrossRef]

66. Bendayan, M.; Zollinger, M. Ultrastructural localization of antigenic sites on osmium-fixed tissues applying the protein A-gold technique. J. Histochem. Cytochem. 1983, 31, 101-109. [CrossRef]

67. Lucocq, J.M.; Habermann, A.; Watt, S.; Backer, J.M.; Mayhew, T.M.; Griffiths, G. A rapid method for assessing the distribution of gold labeling on thin sections. J. Histochem. Cytochem. 2004, 52, 991-1000. [CrossRef]

68. Stirling, J.W.; Graff, P.S. Antigen unmasking for immunoelectron microscopy: Labeling is improved by treating with sodium ethoxide or sodium metaperiodate, then heating on retrieval medium. J. Histochem. Cytochem. 1995, 43, 115-123. [CrossRef] [PubMed]

69. Ghadially, F.N. Ultrastructural Pathology of the Cell and Matrix, 3rd ed.; Wellington Butterworths: London, UK, 1988; pp. 191-328. 